\title{
EFecto de los Precios Administrados SObRe LA INFLACiON
}

\author{
Rafael Gamboa*
}

Documento de Investigación No. 9709

Diciembre de 1997

Banco de México

Dirección General de Investigación Económica

* Agradezco el tiempo e información brindada por el Ing. Marco Antonio Aceves, el Ing. Luis Humberto Villalpando, el Lic. Albino Rodríguez, Cecilia Barra, Alejandro Pérez López y Ariel Yepes. Asimismo quiero agradecer los comentarios de Agustín Carstens, Michael Reinhart, Moisés Schwartz, Rodrigo Valdez, Abraham Vela, Rafael del Villar y Alejandro Werner. Para la realización de este trabajo fue indispensable la asistencia de Demian Castillo y Ana Saavedra. Errores y opiniones corren bajo mi responsabilidad. 


\title{
EFecto de los Precios AdMinistrados SObRe la INFlacion
}

\author{
Rafael Gamboa
}

Diciembre de 1997

Documento No. 9709

\section{RESUMEN}

A lo largo de los años, el Sector Público (SP) en México ha participado directamente en la determinación del precio de un gran número de bienes. La forma en que el SP ha ajustado los precios de los bienes administrados (PA) ha tenido cierto impacto sobre el nivel de inflación. Se han seguido tres estrategias distintas para ajustar los PA. Hasta 1987, el SP controlaba los aumentos en 163 artículos, equivalentes al 36\% del gasto. Como complemento al programa de estabilización de 1987, se fijaron temporalmente los PA, utilizándolos como ancla nominal de la economía. Los constantes rezagos en los PA, que se fueron presentando hasta 1991, crearon fuertes variaciones en precios relativos, lo que contribuyó a que se registraran aumentos abruptos en el nivel de precios. A partir de 1992 se procedió a dejarle al mercado la determinación del precio de los bienes producidos por el sector privado, con lo que la proporción del gasto en bienes con PA bajó al 16\%. Por lo que concierne a los bienes producidos por el SP, a partir de 1992 se anuncian las tasas a las que aumentan mensualmente algunos de éstos, por lo general reflejando la inflación objetivo de las autoridades. Las políticas de liberalización y de ajuste mensual de precios disminuyeron la variabilidad de precios, pero incrementaron el impacto de los aumentos en PA sobre la inflación. Los anuncios de aumentos en los precios administrados tienen hoy un efecto más importante sobre los precios de los bienes libres que en el pasado, al afectar los PA las expectativas de inflación. El efecto de los precios administrados sobre las expectativas de inflación sugiere que resulta factible que el Banco de México utilice metas de inflación para anclar las expectativas inflacionarias de los agentes económicos. 


\section{INTRODUCCION}

2. LAS POLITICAS DE AUMENTOS EN PRECIOS ADMINISTRADOS

3. EFECTOS DE PRECIOS ADMINISTRADOS SOBRE LA INFLACION

3.1 Contribución de Precios Controlados en Planes de Estabilización

3.2 Contribución de los Precios Administrados a la Generación de Inercia Inflacionaria

3.3 Precios Administrados Como Señal de Inflación Futura

3.4 Variabilidad de Precios e Inflación

4. VARIABILIDAD DE PRECIOS RELATIVOS CAUSADA POR ALZAS EN PRECIOS ADMINISTRADOS

5. SEÑAL DE PRECIOS ADMINISTRADOS SOBRE LA INFLACION

6. AJUSTES EN PRECIOS ADMINISTRADOS

7. CONCLUSIONES

\section{REFERENCIAS}

Anexo 1 PRODUCTOS BAJO CONTROL DE PRECIOS Diario Oficial de la Federación (30 de Diciembre de 1982)

\section{Lista de Gráficas}

Gráfica 1 Variabilidad de Precios e Inflación

Gráfica 2 Inflaciones Mensuales

Gráfica 3 Variación de Precios Relativos y Varianza de Theil 
Gráfica 4 Funciones de impulso respuesta para 1985 a 1991

Gráfica 4 Funciones de impulso respuesta para 1992 a 1996

Gráfica 5 Algunos Precios Administrados en Términos Reales (el Promedio es Igual a 1).

\section{Lista de Cuadros}

Cuadro 1 PANEL A Variable Dependiente: INF Muestra: 1986:02 1996:11

Cuadro 1 PANEL B Variable Dependiente: INF Muestra: 1986:02 1996:11

Cuadro 2 PANEL A Variable Dependiente: INF Muestra: 1986:02 1996:11

Cuadro 2 PANEL B Variable Dependiente: INFNAD Muestra: 1986:03 1996:11

Cuadro 3 PANEL A Prueba de Causalidad de Granger Muestra: 1985:01 1996:12 Rezagos: 2

Cuadro 3 PANEL B Prueba de Causalidad de Granger Muestra: 1985:01 1991:12 Rezagos: 4

Cuadro 3 PANEL C Prueba de Causalidad de Granger Muestra: 1992:01 1996:12 Rezagos: 4

Cuadro 4 Variable Dependiente: INF Muestra: 1986:02 1996:11

Cuadro 5 PANEL A Variable Dependiente: INF Muestra: 1986:02 1991:12

Cuadro 5 PANEL B Variable Dependiente: INF Muestra: 1992:01 1996:11

Cuadro 6 PANEL A Prueba de Causalidad de Granger Muestra: 1985:01 1991:12 Rezagos: 3

Cuadro 6 PANEL B Prueba de Causalidad de Granger Muestra: 1992:01 1996:12 Rezagos: 3

Cuadro 6 PANEL C Prueba de Causalidad de Granger Muestra: 1985:01 1991:12 Rezagos: 9 
Cuadro 6 PANEL D Prueba de Causalidad de Granger Muestra: 1992:01 1996:12 Rezagos: 9

Cuadro 7 PANEL A Variable Dependiente: INFNAD Muestra: 1985:11 1991:12

Cuadro 7 PANEL B Variable Dependiente: INFNAD Muestra: 1992:01 1996:12

Cuadro 7 PANEL C Variable Dependiente: INFNAD Muestra: 1995:01 1996:12

Cuadro 8 PANEL A Descomposición de la Varianza de INFNAD Muestra 1985:02-1991:12

Cuadro 8 PANEL B Descomposición de la Varianza de INFNAD Muestra 1992:01-1996:12 


\section{INTRODUCCION}

El sector público en México determina directamente el precio de los bienes que dicho sector produce, el de algunos bienes que reciben subsidios y tienen un fuerte impacto sobre el gasto de los consumidores de bajos recursos, así como el de otros bienes sobre los cuales pocos oferentes tienen considerable poder de mercado. A los precios de estos bienes se les denomina en esta nota precios administrados.

Además del efecto que el sector público puede ejercer sobre el nivel general de precios por medio de políticas macroeconómicas, también participa en la determinación del precio relativo de diversos bienes al fijar o controlar su precio. Entre 1950 y 1991, el sector público controlaba rigurosamente el precio de 163 artículos, práctica que aún continúa ejerciendo sobre más de una decena de bienes. En esta nota se estudia el impacto de las distintas políticas con que se ajustan los precios administrados sobre el nivel general de precios, en adición a la contribución de estos precios a los costos de producción de otros bienes.

En la siguiente sección se relatan las distintas políticas de aumentos de precios administrados en los últimos 12 años. Las políticas han variado de acuerdo con el nivel de inflación, el objetivo de inflación futura que se tenga, el entendimiento de la sociedad sobre la efectividad y eficiencia de los controles de precios y las necesidades de finanzas públicas. La amplia experiencia con diversas prácticas ha llevado a un consenso entre economistas y encargados de las políticas públicas en el mundo, sobre los efectos nocivos de controlar precios en niveles distintos a sus valores de mercado. Los controles de precios afectan el abasto de bienes y servicios, la innovación en la industria, las prácticas competitivas, los déficit públicos y crean distorsiones en precios relativos. Por ello, en México, sin que haya desaparecido la preocupación de mantener el poder de compra de los consumidores sobre artículos básicos, ha habido una evolución hacia una menor participación del gobierno en la fijación de precios de bienes producidos por el sector privado. No obstante, los bienes en los que aún participa el sector público en la determinación de sus precios todavía representan una proporción significativa del gasto de los consumidores (16\%).

Al ser los bienes administrados parte de la canasta de consumo, un alza en sus precios se registra como un aumento en el nivel general de precios. Sin embargo, esto último no significa necesariamente que la inflación se haya elevado, o sea, que el aumento en precios administrados promueva el alza generalizada y sostenida de los precios. El incremento referido puede ser un ajuste en el precio relativo de los bienes administrados sin consecuencia sobre el aumento del precio de bienes que no utilizan a los bienes administrados como insumos. No obstante, se han esgrimido en la literatura diversos argumentos teóricos mediante los cuales se sugieren diversos canales a través de los cuales los precios administrados pueden impactar a la inflación; éstos se revisan en la tercera sección.

Existen tres razones por las cuales el aumento en los precios administrados puede generar presiones inflacionarias. Primero, cuando los precios administrados están indizados a inflaciones o ajustes salariales o de tipo de cambio sucedidos con anterioridad, estos precios contribuirán a que se genere inercia inflacionaria. Si los precios administrados aumentan sistemáticamente en relación con inflaciones pasadas y los precios libres también siguen ese patrón de ajuste, la autoridad monetaria podría instrumentar su política con base en inflaciones anteriores y propiciar así la inercia inflacionaria. 
Segundo, aumentos en precios administrados elevan el nivel general de precios en el corto plazo si el resto de los precios no se ajusta a la baja. Ante un desarreglo de precios relativos que no pueda corregirse con diminuciones de precios, la autoridad monetaria podría optar por acomodar el alza en precios administrados. Este tipo de reacción ocasionaría que aumente el nivel de precios aún en el largo plazo. Tanto el efecto de corto como el de largo plazo recién mencionados, han sido señalados en la literatura y confirmados en distintos países y periodos. El aumento de inflación en el corto plazo se ha observado a través de la correlación positiva entre el nivel de inflación y la variabilidad de precios. En México también se observan inflaciones mayores en el corto plazo ante aumentos en la variabilidad de precios relativos. En la gráfica 1 se muestra que la inflación mensual es más elevada cuando la variabilidad de precios relativos es mayor, tanto de los bienes administrados como la de los no administrados. ${ }^{1}$ Sin embargo, en México actualmente no se observa que los aumentos en precios administrados se traduzcan en una mayor inflación un año después de sucedidos, lo que implica que las variaciones en precios relativos no han sido acomodadas por la política monetaria. Esta relación se estudia con mayor detalle en la cuarta sección.

\section{Gráfica 1}

Variabilidad de Precios e Inflación

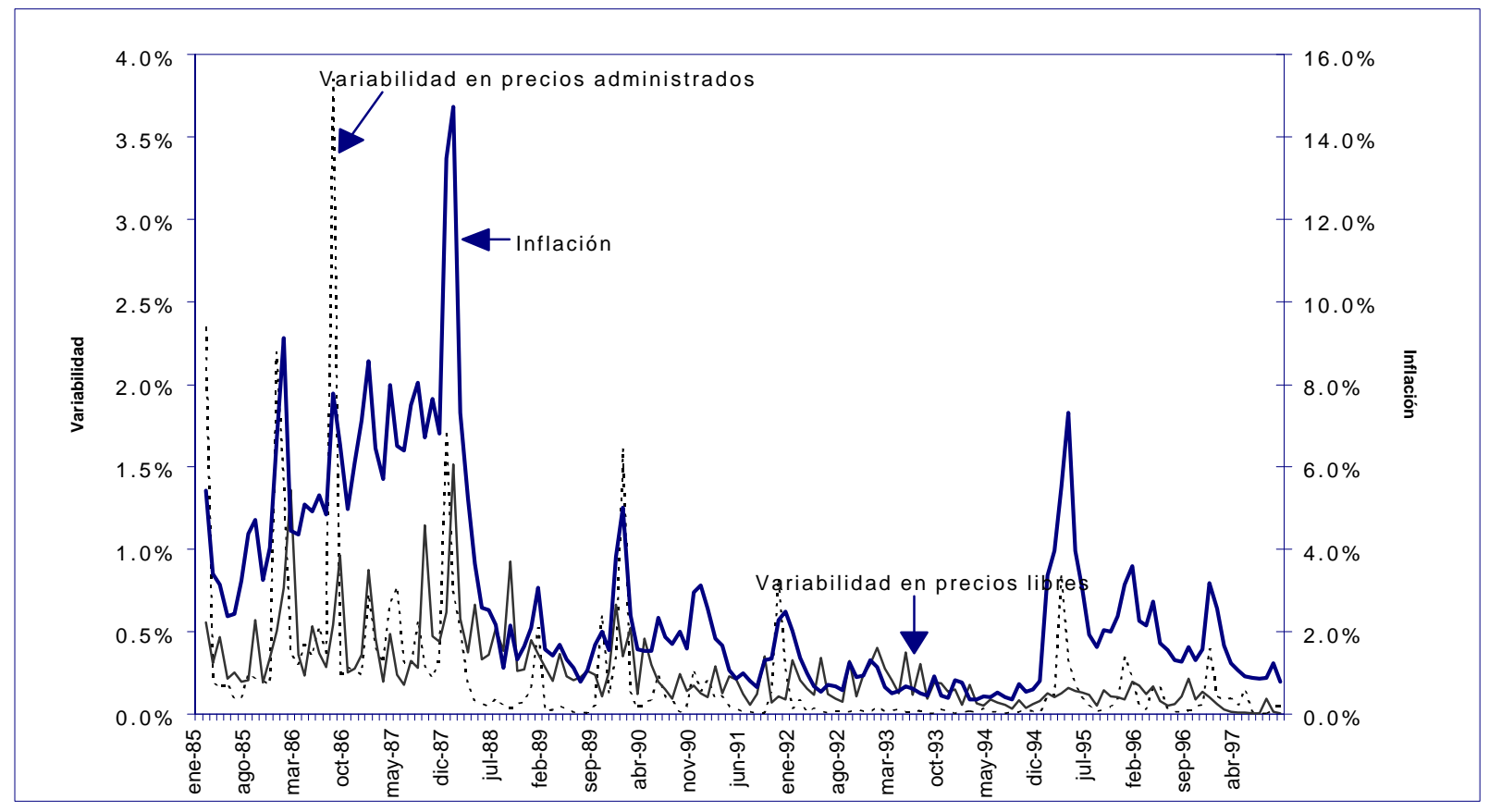

Tercero, los precios administrados pueden contener información sobre la inflación futura. Esta vía, por la que el sector público afecta a la inflación, se explora en la quinta sección de este documento. Por ejemplo, entre 1988 y 1989 se utilizaron los precios administrados como ancla nominal. Como parte del programa de estabilización iniciado en noviembre de 1987, se le dio un ajuste mayúsculo a los precios administrados, dejándoles prácticamente inalterados por los siguientes dos años. Al reducirse la tasa con la que aumentaban los precios administrados, estos

1 La variabilidad se mide utilizando la varianza de Theil, la cual se explica más adelante. 
precios funcionaron como un ancla nominal adicional al tipo de cambio. Es decir, los precios administrados contribuyeron a que las expectativas de inflación del público se coordinaran en torno a un nivel significativamente menor. En épocas recientes (desde 1992 a la fecha) se ha observado nuevamente que las alzas en los precios de los bienes administrados tienen un impacto significativo sobre los aumentos de los precios de los bienes libres. Los aumentos en los precios administrados proveen en la actualidad mayor información sobre aumentos en los precios libres que en el periodo 1985-1991. Los precios administrados tienen mayor influencia sobre el aumento de precios libres debido a que gran parte de sus ajustes se anuncian con anticipación, por lo que los aumentos en ambos tipos de precios resultan similares. Por otra parte, los aumentos en precios administrados son ahora más independientes de los otros canales que contribuyen a crear inflación, por lo que resulta más fácil discernir su influencia sobre el aumento general de los precios.

Desafortunadamente, este conocimiento de las influencias de los distintos mecanismos con que se ajustan los precios administrados sobre la inflación resulta de poca utilidad para predecir aumentos en precios administrados. Utilizando herramientas estadísticas no es posible determinar con altos niveles de confianza el nivel futuro de los precios administrados debido a que, como se muestra en la sexta sección, los precios reales de estos bienes presentan importantes y persistentes desviaciones de lo que podría considerarse como un nivel de equilibrio y tampoco muestran un comportamiento cíclico regular. El mejor pronóstico de estos precios se puede efectuar sólo si se conoce la política de subsidios que afecta su determinación.

La séptima sección presenta algunas conclusiones del impacto de los precios administrados sobre la inflación, así como algunas recomendaciones de política para evitar que los ajustes en dichos precios propicien mayor inflación, y por consiguiente, dificulten el abatimiento de los precios en la economía mexicana.

\section{LAS POLITICAS DE AUMENTOS EN PRECIOS ADMINISTRADOS}

México tiene una larga tradición operando con precios administrados. En 1950 el poder legislativo autorizó al ejecutivo en las llamadas "Atribuciones del Ejecutivo Federal en Materia Económica" a controlar el precio de los bienes y servicios que el propio ejecutivo juzgara conveniente. Hasta 1974, la Secretaría de Industria y Comercio fijó el precio máximo de los bienes controlados. Sin embargo, en ese año, la creciente inflación tornó este esquema obsoleto y requirió que se adoptara un mecanismo denominado "Fijación de Precios por Variación de Costos", que permitió que algunos precios se ajustaran a la inflación. Por otra parte, ciertos bienes se mantuvieron sujetos a control rígido (fijos). Entre otros, los precios y tarifas del sector público, en parte siguiendo una política propia del "desarrollo estabilizador" que buscaba mantener bajo el costo de energía para los productores, pero principalmente por el problema político que generaba durante esa época el ajustar estos precios y por la incapacidad de los administradores de las empresas paraestatales en el establecimiento de precios adecuados (Gil Díaz, 1983).

El presente análisis se concentra en el periodo de enero de 1985 a noviembre de 1997, el cual presenta diferentes esquemas de control de precios, asociados con diversas circunstancias políticas, económicas y objetivos de inflación. A continuación se analizan en mayor detalle las políticas de control de precios en el periodo señalado. 
En diciembre de 1982 se emitió un decreto que diferenciaba los artículos sujetos a control rígido, aquéllos sujetos a control flexible (132 artículos entre ambos) y 31 artículos sujetos a registro. En todos los productos bajo control, el gobierno establecía el precio máximo que los vendedores podían cobrar. Aquellos bienes bajo control flexible tenían un régimen que permitía aumentos cuando aumentaban los costos. Los productos sujetos a registro tenían que reportar su precio ante la Secretaría de Comercio y Fomento Industrial (SECOFI), y cuando ésta lo juzgaba necesario, se autorizaba su aumento. A partir de mediados de 1985, con el aumento de la inflación, las solicitudes de aumento se hicieron más frecuentes, lo que requirió de un mecanismo de respuesta más ágil por parte de la SECOFI, por medio del cual se aprobó mensual y automáticamente que se realizaran aumentos de precios de los productos sujetos a control que reflejaran el $100 \%$ de la devaluación y el $80 \%$ de la inflación observada. ${ }^{2}$

Este esquema de indización con base en la inflación pasada le impuso cierto grado de inercia al sistema de actualización de precios, lo que representaba un obstáculo para el éxito del programa de estabilización iniciado a finales de 1987. Por ello, fue necesario modificar el esquema de control de precios con el objetivo de eliminar la inercia inflacionaria y contribuir a la coordinación de expectativas de inflación en torno a un nivel decreciente. Es decir, los precios administrados se utilizaron como un ancla nominal más, en adición al tipo de cambio y las negociaciones salariales. De tal forma, los 163 productos controlados pasaron a estar sujetos al mismo régimen, bajo el cual todo aumento requería de aprobación de los sectores firmantes del Pacto de Solidaridad Económica (PSE). ${ }^{3}$ En diciembre de 1987 se negoció un aumento considerable para ajustar el precio inicial de los bienes sujetos a control, para posteriormente, a partir de abril de 1988 y hasta el final del PSE permanecer prácticamente inalterados (con excepción de un ajuste menor a finales de 1988). ${ }^{4}$ En la gráfica 2 se puede observar la evolución de los precios administrados y la de los precios libres, con las alzas en precios libres excediendo a los controlados desde principios de 1988 hasta finales de 1989.

En enero de 1989 se inició la segunda fase del programa de ajuste denominada Pacto para la Estabilidad y el Crecimiento Económico (PECE). En esta etapa se presentaron ajustes en los precios y tarifas del sector público en enero de 1989, noviembre de 1990 y diciembre de 1991, permaneciendo constantes por el resto del tiempo comprendido entre 1989 y $1992 .^{5}$ Por otra parte, se acordó que los precios de los otros productos controlados se ajustarían en negociaciones con cada sector. Estas negociaciones consistían en un dictamen que se elaboraba con base en el estudio de costos y utilidades de las empresas que componían al sector. Aquellos bienes que tenían un ponderador muy importante en el índice de precios, eran evaluados por la

2 Para un análisis más detallado de la evolución de los controles de precios hasta 1991 véase Dávila (1991).

${ }^{3}$ Es importante señalar que el Pacto original contemplaba hacer los ajustes de precios y salarios mensualmente a partir del 1o de marzo de 1988, tomando en cuenta la inflación prevista con la idea de que no hubiera "ajustes abruptos ni presiones inflacionarias excesivas" (Serra, 1987).

4 De hecho los empresarios acordaron para el periodo de septiembre a diciembre reducir sus precios en un $3 \%$.

5 Como ya se mencionó, originalmente se contempló hacer un ajuste mensual; posteriormente, el gobierno se comprometió a mantener fijos precios y tarifas durante el periodo que durara la concertación, por lo que el público desconocía el momento en el que se realizaría el ajuste. En 1988 hubo 5 concertaciones, 2 en 1989 , 2 en 1990 y 1 en 1991. Asimismo cabe resaltar que en un par de ocasiones no se respetó el término originalmente acordado. 
subcomisión de precios para ser aprobados por la Comisión de Evaluación y Seguimiento del PECE.

\section{Gráfica 2}

Inflaciones Mensuales

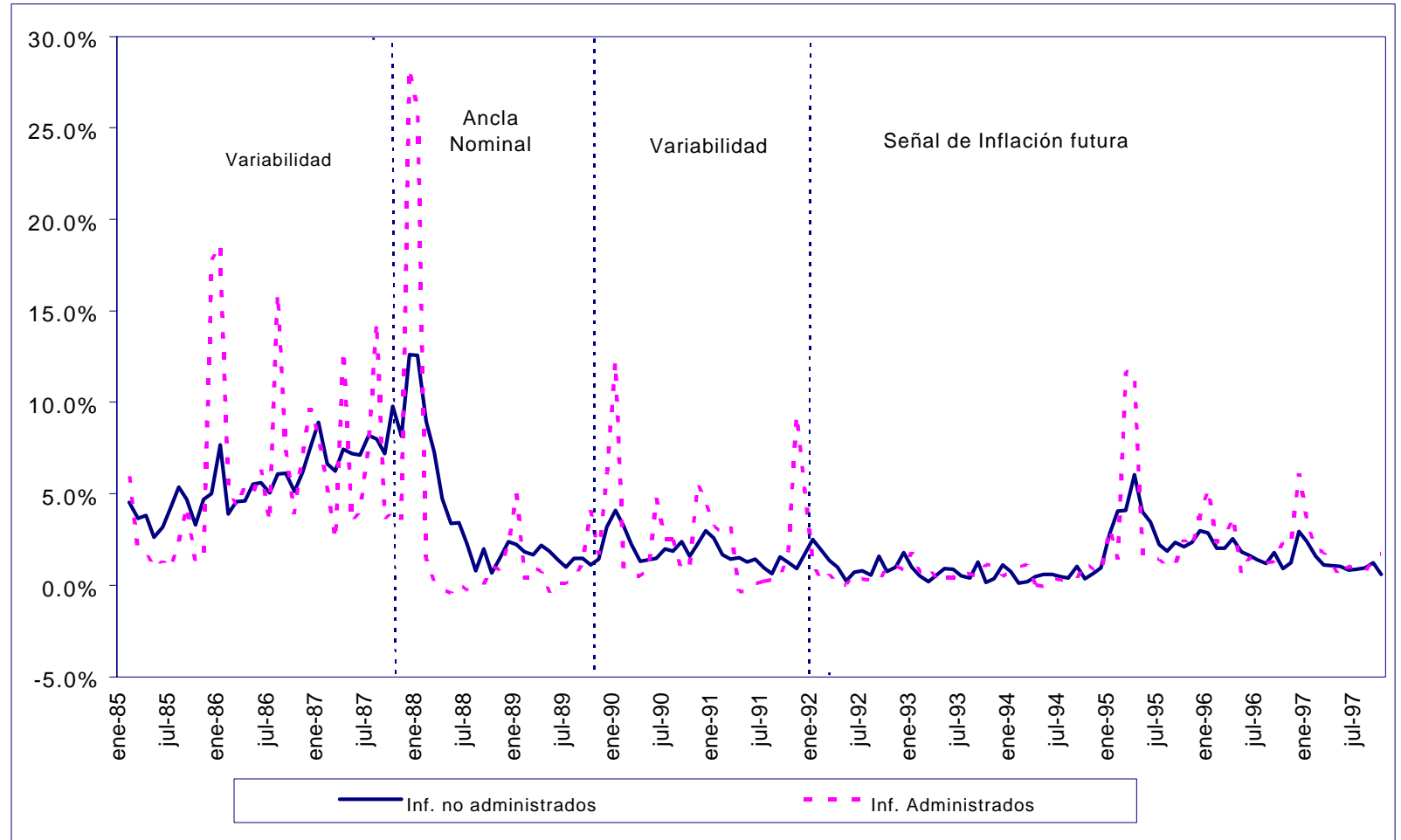

Hacia 1992 se estableció una nueva categoría para controlar precios: la flexibilización. Mediante ésta, los empresarios moderaban sus demandas por mayores precios a cambio de medidas gubernamentales de apoyo al sector. Este fue el primer paso hacia la eliminación del control de estos precios, puesto que se negociaba un precio real objetivo del sector y una trayectoria de ajuste hacia el mismo. Además, el número de bienes controlados se redujo de 115 en 1989 a 91 en 1991 (17 de los liberados eran bienes de siderurgia), mientras que el de flexibilizados aumentó de 18 (entre los que estaban los siderúrgicos) a 60. Cabe mencionar que el propósito de los controles en esta época nunca fue eliminar los aumentos en precios, sino coordinar las expectativas de inflación hacia la baja evitando el desabasto y que se incurriera en déficit fiscales. Debido a que los aumentos se presentaban durante las concertaciones para permanecer prácticamente fijos por un tiempo prolongado, los aumentos de precios administrados generaban un desarreglo temporal en los precios relativos. Esto es, la variabilidad de los precios relativos era mayor cuando se implementaban las alzas de las concertaciones. Esta mayor variabilidad también se presentaba durante los ajustes de precios del periodo previo al programa de estabilización.

Desde 1992, la estrategia a seguir en cuanto al establecimiento de precios y tarifas del sector público cambió en forma trascendente. A partir de entonces el precio de las gasolinas, gas y electricidad se ajustó periódicamente, con base en una tasa de desliz mensual, la cual reflejaba la inflación esperada durante el siguiente periodo de revisión del PECE. Por lo que concierne a los bienes controlados producidos por el sector privado, se renovó el compromiso de seguir 
evaluando caso por caso sus aumentos. Bajo el espíritu de que los precios se aproximaran a sus valores de mercado, la flexibilización pasó a ser un periodo de transición hacia la liberalización paulatina de un gran número de bienes. Después de la liberalización de los productos siderúrgicos en septiembre de 1989, la mayor parte de los bienes controlados se liberalizó entre abril de 1993 y marzo de 1994 (el cuadro del Anexo 1 contiene las fechas en que se liberalizaron los precios de los distintos bienes de consumo). A estos bienes les siguió el azúcar, que se liberalizó en agosto de 1995; la mayor parte de los tipos de leche, que se liberaron en diciembre de 1996; mientras que la tortilla, harina de maíz, leche pasteurizada y medicinas aún permanecen bajo control, lo mismo sucede con telefonía local y transporte público en el D.F. ${ }^{6}$ Estos cambios hicieron que los aumentos en precios administrados $y$ no administrados tuvieran un comportamiento muy similar a partir de 1992 (periodo de "señal de inflación futura" en la gráfica 2).

El alza en el precio de bienes comerciables e insumos importados, como consecuencia de la devaluación de 1994, frenó de manera importante el avance en el control de la inflación. La incertidumbre sobre la futura evolución de la tasa de inflación, reflejada en altas tasas de interés, hizo imposible realizar los ajustes adecuados en los precios públicos. Por ello, durante un tiempo fue inútil el esfuerzo de coordinar expectativas de inflación en torno a un nivel creíble. Fue así como las prioridades del sector público se reorientaron hacia el ajuste fiscal, la estabilización de los mercados financieros y la solución del sobreendeudamiento del sector privado. En consecuencia, los precios de los bienes producidos por el sector público aumentaron fuertemente tanto en marzo como en octubre de 1995, como parte de la consolidación fiscal requerida.

En octubre de 1995, una vez que se logró la estabilización de las principales variables macroeconómicas, se firmó un nuevo acuerdo entre gobierno, obreros y empresarios, la Alianza para la Recuperación Económica (ARE). Los objetivos del ARE eran mantener la planta productiva y elevar el empleo, consolidar la estabilidad financiera y el equilibrio de cuenta corriente, y aumentar la competitividad de la economía. El descenso de la inflación era nuevamente uno de los objetivos puesto que sin el abatimiento de los precios no se lograría la estabilidad financiera.

La liberalización fue palpable en los fuertes aumentos registrados en los precios de los bienes básicos durante el segundo semestre de 1995 y primero de 1996. Estos aumentos fueron consecuencia de la devaluación y del aumento en el precio internacional de bienes agropecuarios e hidrocarburos, lo que muestra que la liberalización ha vuelto más sensibles a los precios nacionales al tipo de cambio y al precio de los bienes comerciables. Por otra parte, si bien continúa la política de aplicar una tasa de aumento mensual al precio de gasolinas, gas y electricidad, también es cierto que estos bienes han presentado fuertes aumentos al inicio de cada periodo de ajuste mensual. Esto se debe a que los precios internacionales de gasolinas y gas aumentaron durante 1995 y principios de 1996 (aún en términos de dólares), mientras que los insumos que determinan el costo marginal de proporcionar electricidad aumentaron debido a la devaluación. Por ello y debido también al error de pronóstico acerca de las inflaciones de 1995 y 1996, los ajustes mensuales de acuerdo con la inflación no reflejaron los precios de referencia o los costos. A finales de 1995 y de 1996 se incrementaron los precios públicos en términos reales

${ }^{6}$ Se tiene contemplado liberalizar leche y medicinas en 1998. 
y se optó por hacer incrementos mensuales en gas y electricidad por encima de la inflación. Por esta razón, lo más apropiado para evitar subsidios y rezagos sería indizar los precios de bienes administrados directamente a su precio de referencia y costos marginales en forma periódica.

En conclusión, tanto la liberalización como el cobro racional de precios por el sector público han implicado una mayor dependencia del índice de precios de la evolución del tipo de cambio y de los precios internacionales. Por su parte, los precios de bienes producidos por el sector público se ajustan conforme a la inflación proyectada para el periodo siguiente para evitar "retrasos". Parecería ser que ésta es la mejor política. Sin embargo, al estar ligado el precio de estos bienes a factores distintos a la inflación doméstica, en ocasiones se deben presentar ajustes considerables a fin de adecuarlos a sus costos o precios de referencia. ${ }^{7}$ En consecuencia, para evitar ajustes mayúsculos, sería conveniente indizar periódicamente los precios administrados a sus precios de referencia y costos, dejando el ajuste exclusivamente conforme a la inflación proyectada para bienes con costos nacionales (como peajes de carreteras) y subsidios por unidad del bien (en electricidad y tortillas). Alternativamente, se puede continuar con la indización a la inflación proyectada constituyendo fondos que permitan cubrir las diferencias temporales entre aumentos en costos y el nivel general de precios.

\section{EFECTOS DE PRECIOS ADMINISTRADOS SOBRE LA INFLACION}

Los controles de precios tienen una larga y poco grata tradición dentro del análisis económico. El poco aprecio por los controles se deriva de los problemas microeconómicos que éstos ocasionan en mercados competitivos. Al establecerse el precio de un bien por encima del nivel donde se encuentran oferta y demanda (como un salario mínimo o un precio de garantía) se genera un exceso de oferta por el que se desperdician los bienes al no encontrar consumidores, por lo que se requiere de un sistema distinto al de mercado para distribuir aquellos bienes o factores que encuentran mercado. En el caso contrario, en el que se fija el precio por debajo del nivel de mercado, se crea un exceso de demanda, puesto que se producen menos bienes $u$ ofrecen menos recursos de los que se quieren consumir o emplear. En este caso, para determinar quién tiene acceso a los bienes, se crean mercados negros o se hacen colas.

Sin embargo, existen algunas fallas en el funcionamiento del mercado que requieren que los precios se regulen, tales como la existencia de monopolios naturales. En este documento el énfasis se hace en el impacto macroeconómico de los controles de precios.

\subsection{Contribución de Precios Controlados en Planes de Estabilización}

En el contexto macroeconómico, la literatura es menos abundante que en el caso microeconómico pero ésta proporciona una razón válida para su establecimiento. Un gobierno que tiene el objetivo de disminuir la inflación pero carece de credibilidad, enfrentará expectativas de inflación mayores a la inflación objetivo. Esto es, el público no cree en la inflación objetivo de la autoridad debido al costo que para el gobierno representa disminuir la inflación, tanto debido a que reduce sus ingresos como porque, con mayores precios, puede compensar otras

\footnotetext{
${ }^{7}$ Cabe aclarar de que si el precio relativo de los bienes producidos por el sector público es estable, la diferencia que se presentará en los precios de estos bienes, siguiendo un ajuste con base en el costo marginal de aquel que lo hace con base en la inflación futura, provendría de la diferencia entre inflación interna y los aumentos del tipo de cambio nominal, diferencia que bajo un tipo de cambio flexible tendería a ser de breve duración.
} 
distorsiones existentes en la economía (Barro y Gordon, 1983). Si los productores establecen precios mayores a los que los consumidores pueden pagar con el dinero que reciben de la autoridad monetaria, se contrae la demanda por bienes, por lo que se genera una recesión. Por ello, sería conveniente que todos los agentes en la economía coordinaran sus expectativas en torno al nivel de inflación objetivo. De existir un problema de credibilidad en el compromiso del gobierno para abatir la inflación, se justifica el uso temporal de controles de precios, como medidas adicionales al control monetario y fiscal (Bruno, 1990). Esta fue la razón por la que la mayoría de los planes de estabilización puestos en marcha en la segunda mitad de la década de los ochenta incluyeron controles de precios; comprendiendo entre éstos a los de Israel y México considerados como exitosos. Esto países, al tener una tradición de controles de precios, contaron con un instrumento adicional para disminuir el problema de credibilidad. La forma en que se controlen los precios contribuye a que se logre el objetivo.

El control del precio de distintos bienes es un elemento más en apoyo a las políticas monetaria y fiscal para que disminuya el nivel de inflación, pero conlleva el problema de establecer el nivel de estos precios. Se podría pensar que si el fin de la política es bajar la inflación, la política más apropiada sería hacer que los precios aumentaran precisamente a la tasa de inflación objetivo. Sin embargo, esta política no es factible debido a que al público le es más fácil vigilar el cumplimiento de acuerdos sobre niveles de precios que sobre niveles de aumentos de éstos. Por ello, típicamente se fija el precio nominal de dichos productos, por lo que el ancla solamente debe utilizarse de manera temporal.

Invariablemente en las economías de mercado se cuenta con bienes cuyo precio no puede controlar el sector público. Dado que el precio de estos bienes seguirá en ascenso debido a que la inflación no se elimina del todo, el precio real de los bienes controlados descenderá. Debido a esta pérdida esperada, normalmente los planes de estabilización presentan un aumento inicial en el precio de los bienes controlados para fijarse posteriormente. El factor inercial que presentan los precios libres y la poca credibilidad al inicio del programa de ajuste dificultan y alargan la transición. Por ello, en algunos casos el precio real de los bienes controlados se reduce a niveles en los cuales no conviene producirlos, generando con ello desabastos significativos (40\% un año después del lanzamiento del plan Cruzado en Brasil y 20\% en Argentina durante el plan Austral) o en los que genera un deterioro de las de finanzas públicas (con el Cruzado las tarifas públicas se mantuvieron constantes por nueve meses, mientras que en el Austral lo estuvieron por ocho, ambos aún con elevados niveles de inflación) (véanse Aspe, 1992, y Larraín, 1996). Es por ello que las autoridades deben ser cuidadosas del desabasto que generen los controles y efectuar ajustes posteriores en estos precios, antes de que caiga el abasto de productos y de que el público espere mayores niveles de inflación al deteriorarse las finanzas públicas.

Los ajustes iniciales a los precios controlados se hacen para compensar la pérdida que en términos reales presentan estos bienes durante la primera etapa del programa de estabilización. Estos ajustes deben ser acordes con la inflación objetivo, de otra forma es posible que no se cumpla con el propósito de abatir la inflación debido a que se generan dos problemas: por una parte se puede imprimir nueva inercia a la inflación y por otra, con aumentos esporádicos y abruptos, hay mayor variación de precios relativos, lo que en sí mismo puede generar presiones inflacionarias. 


\subsection{Contribución de los Precios Administrados a la Generación de Inercia Inflacionaria}

Primeramente, cuando el ajuste de los precios administrados se hace con rezagos, se incorpora en el aumento la inflación que se presentó con anterioridad y no la inflación esperada en el futuro. Esto hace que los precios de los bienes que utilizan estos bienes como insumos se incrementen con base en la inflación pasada. Asimismo, los precios de los bienes sustitutos y complementarios ajustan su precio relativo incorporando con ello inflaciones anteriores. Esto le adhiere inercia al sistema de ajuste de precios, al depender la inflación del periodo presente de la del mes anterior, dificultando con ello la transición hacia un escenario con menor inflación (Taylor, 1983). Para evitar esta inercia, los precios administrados deben aumentarse de acuerdo con la inflación esperada en el futuro y no rezagarse. Al comprometerse con estos aumentos, las autoridades dan una señal sobre el nivel de inflación que esperan en el periodo venidero.

\subsection{Precios Administrados Como Señal de Inflación Futura}

Los precios administrados, como decisión del sector público, proporcionan al público una señal de la inflación que anticipa el sector público, y como tal afectan las expectativas de inflación futura. Esta función de señalización es precisamente la que se aprovecha para coordinar expectativas al poner en marcha planes de estabilización (Cukierman, 1988). Al ajustar los precios públicos conforme a la inflación esperada, la autoridad debe establecer dos parámetros: el nivel inicial del precio y el ajuste mensual posterior. El aumento inicial tiene la finalidad de adecuar el precio del bien a un nivel real sostenible, mientras que la tasa de aumento mensual sirve para mantener ese nivel real constante. Al anunciarse con anticipación aumentos reales y ajustes inflacionarios, esta práctica ha incrementado el papel que juegan los precios administrados como señal de inflación para el resto de los bienes. Esto se ha traducido en que los precios administrados tengan un efecto más sensible sobre el nivel de inflación. Los aumentos reales se manifiestan de inmediato y de una vez por todas sobre el nivel de precios. Además, los ajustes periódicos que divergen de la inflación esperada por el público contribuyen a modificar las expectativas de inflación futura.

De esta manera se pueden utilizar los bienes administrados para coordinar expectativas de inflación en torno a un nivel de inflación. Sin embargo, debido a que la inflación proyectada y los aumentos en los costos marginales de los bienes difieren en ocasiones, se hacen ajustes posteriores en el nivel real. El resultado es que el ajuste de los precios administrados cambia los niveles de inflación y por ende dificulta el que se alcance un objetivo de inflación si los ajustes no se toman en cuenta desde que se define la meta. En este sentido la prescripción de política económica sería hacer los ajustes más acordes con los cambios en los costos marginales de los bienes o hacer los ajustes mensuales con base en la inflación objetivo, constituyendo un fondo que cubriera las diferencias temporales entre aumentos en costos e inflación.

\subsection{Variabilidad de Precios e Inflación}

La variación en precios administrados contribuye a que aumente la inflación. Existe una abundante literatura empírica iniciada hace más de un siglo que ha encontrado una fuerte relación entre el nivel de inflación y la variabilidad de los precios relativos (por ejemplo, Vining y Elwertowski, 1976). Sin embargo, la teoría que explica esta correlación es menos sólida. Economistas de todas las épocas, desde Jevons hasta Friedman, han hecho hincapié en que el cambio en el precio relativo de los bienes no tiene porqué verse reflejado en un aumento en la 
inflación. De hecho, la explicación más frecuente ha sido que la causalidad va en el sentido de aumentos en la inflación que crean mayores variaciones en precios relativos. Esta causalidad se debería a que la información sobre el aumento en la oferta monetaria llega de manera desigual a los diferentes mercados o porque existen distintos costos de cambiar los precios de los bienes, por lo que los aumentos se desfasan. Pero la causalidad bien podría ser la contraria: al aumentar el precio de algunos bienes, con el respectivo aumento en la variabilidad de precios relativos, deberían bajar los precios de otros bienes, pero estas bajas serían tan pequeñas que probablemente no convendría pagar el costo de modificar los precios, lo que se reflejaría en una mayor inflación promedio (Ball y Mankiw, 1995). Este argumento requiere que los aumentos en los precios sean muy superiores a las bajas en los mismos, esto es, que la distribución de precios sea asimétrica. En un contexto de inflación positiva, los aumentos y las bajas serían con respecto a la media de la distribución de aumentos de precios. Empíricamente se ha comprobado la relación positiva entre el sesgo positivo de la distribución de aumentos de precios (tercer momento de la distribución) y la inflación (que es similar a la media de esta distribución). Esto es, los aumentos abruptos en algunos precios hacen que aumente el nivel general de precios por encima de lo que indicaría la expansión monetaria. Es necesario agregar que, después de transcurrido cierto tiempo, los precios tenderían a realinearse y el efecto inflacionario de los aumentos abruptos se disiparía.

Ante la presencia de choques de oferta producidos por cambios en los términos de intercambio o por desastres naturales, se generan aumentos en los precios de los bienes afectados, y éstos podrían tener un fuerte impacto sobre el índice de precios, ya sea porque se trata de insumos para la producción o porque son bienes de consumo generalizado. En un contexto de inflexibilidad a la baja en precios, se requeriría de una caída en la producción para compensar el desajuste. En ciertas circunstancias, el efecto recesivo de estos aumentos se puede (y debe) contrarrestar parcialmente con una política monetaria activa, lo que repercute en un aumento en el nivel de precios aún en un plazo más largo (Fischer, 1981). Los aumentos en precios administrados después de acumular fuertes rezagos generan choques de oferta de escala menor, pero suficiente para afectar el nivel de precios cuando menos en el corto plazo. Inclusive Cukierman y Leiderman (1984) sostienen que el efecto de la variabilidad de precios administrados sobre la inflación no desaparece cuando inesperadamente estos precios no aumentan en un mes, puesto que dejan en manos de los consumidores mayores saldos de dinero que pueden ser usados en la compra de los bienes no controlados. ${ }^{8}$ Por todo lo anterior, se concluye que en la medida en que los precios controlados se desfasen del aumento en sus costos marginales, su variabilidad contribuirá positivamente a la inflación. Esta correlación se analiza en la siguiente sección y se hace un esfuerzo por establecer la dirección de causalidad entre inflación y variabilidad de precios relativos.

8 Este argumento requiere que los consumidores tengan cierto grado de ilusión monetaria (en cuyo caso se observaría que bajarían los precios de los bienes libres durante los periodos de aumento en precios administrados), o que la autoridad monetaria acomodara los aumentos en precios administrados, o bien que el diferir el aumento constituya un subsidio y que no se presente la equivalencia ricardiana. 


\section{VARIABILIDAD DE PRECIOS RELATIVOS CAUSADA POR ALZAS EN PRECIOS ADMINISTRADOS}

La variabilidad en precios relativos contribuye al aumento en el nivel general de precios. Para que el nivel general de precios permaneciera inalterado al subir en forma abrupta el precio de los bienes públicos, se requeriría que otros precios descendieran. Pero si hay inflexibilidad a la baja en precios o el ajuste señalado se da después de varios meses, el nivel general de precios aumentará en el corto plazo.

Los estudios revisados en la sección anterior, en su mayoría, miden la variabilidad de precios haciendo uso de la variabilidad de Theil, que para cualquier agrupación de precios de bienes que se quiera hacer en el mes $t$ es igual a:

$$
\text { VARGrupo }_{\mathrm{t}}=\sum_{\mathrm{i}=1}^{\mathrm{N}}\left(\mathrm{w}_{\mathrm{i}} / \Omega_{\text {Grupo }}\right)\left(\pi_{i, t}-\pi_{t}\right)^{2} \text {. }
$$

Donde $w$ es el ponderador que tiene el bien en la canasta de consumo; $\Omega_{\text {Grupo }}$ es la ponderación agregada de todos los bienes que integran al grupo; $\pi_{i}$ es el cambio proporcional en el precio del bien $i$ con respecto al mes anterior; y $\pi$ es la inflación mensual del índice de precios al consumidor.

Sin embargo, esta medida, por construcción, tiene el inconveniente de aumentar con la inflación. De utilizar este indicador en una regresión de inflación, se podrían sesgar los resultados en favor de la hipótesis de correlación positiva entre inflación y variabilidad. Debido a que el objetivo es examinar la contribución a la inflación de la medida en la que se desvíen los precios individuales del promedio, se mide la desviación de los precios relativos individuales. Esto es, el cambio en el precio relativo de cada bien mes con mes:

$$
\frac{\frac{p_{i, t}}{I P C_{i, t}}-\frac{p_{i, t-1}}{I P C_{i, t-1}}}{\frac{p_{i, t-1}}{I P C_{i, t-1}}}=\frac{\pi_{i, t}-\pi_{t}}{1+\pi_{t}}
$$

Donde $p_{i, t}$ es el precio del bien $i$, en el tiempo $t$ e IPC es el índice de precios al consumidor. Esta medida estandariza por el nivel de inflación existente. De tal forma que la ecuación (3) define al indicador de la variabilidad en precios relativos utilizado en este documento:

$$
\text { VAREL }_{t}=\sum_{i=1}^{N}\left(w_{i}\right)\left(\frac{\pi_{i, t}-\pi_{t}}{1+\pi_{t}}\right)^{2} .
$$

La gráfica 3 muestra que ambas medidas de variabilidad resultan ser muy similares en el periodo analizado. De hecho, las regresiones posteriores muestran cualitativamente los mismos resultados con ambas variables, solamente en el periodo previo a 1990 se observa que (1) es sensiblemente mayor que (3). 


\section{Gráfica 3}

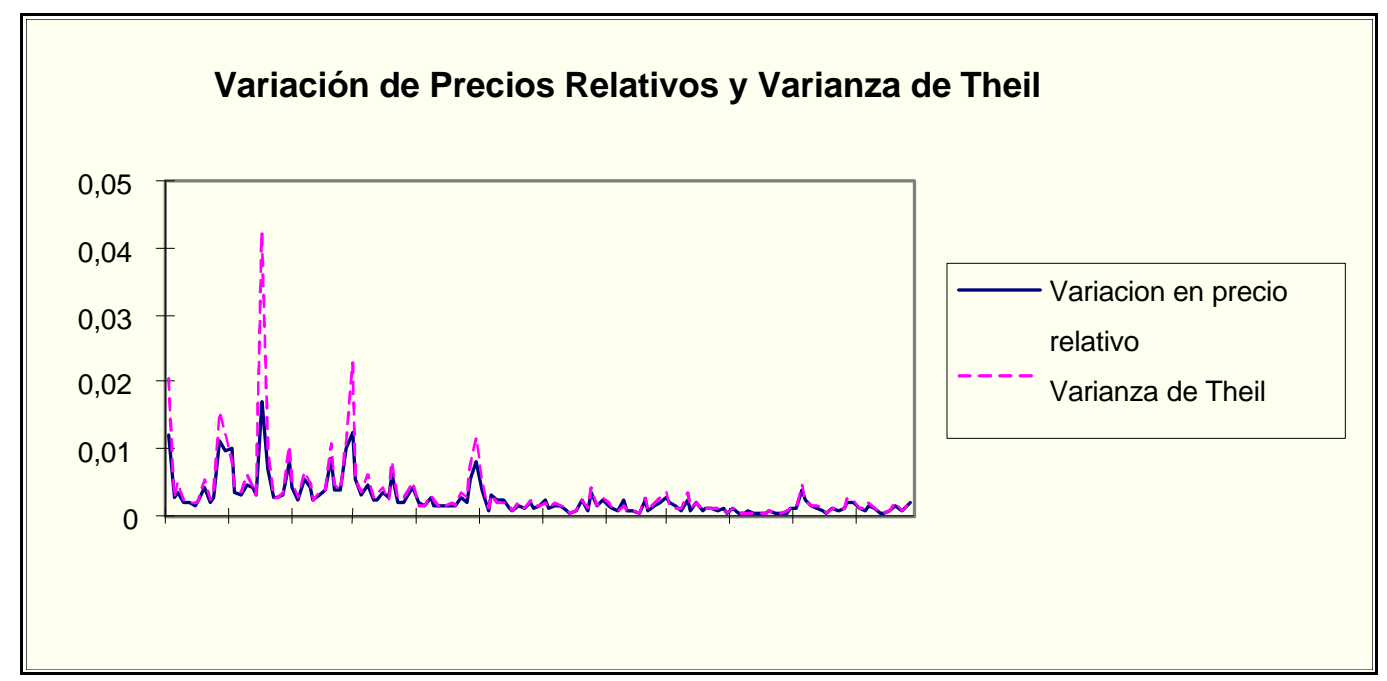

Con el fin de separar el efecto de la variabilidad de precios de los otros canales que impactan sobre la inflación se utiliza, siguiendo a Coorey et al. (1997), una regresión de inflación, a la que además de los componentes tradicionales asociados con la inflación, como cambios en oferta de dinero, en tipo de cambio, en salarios, y rezagos de la inflación, se agrega la variabilidad de precios relativos. ${ }^{9}$ Esto es, se estima la ecuación de regresión (4):

$$
\pi_{t}=\beta_{0}+\beta_{1} \Delta M_{t}+\beta_{2} \Delta w_{t}+\beta_{3} \Delta T C_{t}+\beta_{4} \pi_{t-1}+\varepsilon
$$

a la que se agregaría como variable exógena la variabilidad de precios relativos (VAREL).

Donde $\Delta M$ es el cambio en la oferta monetaria, $\Delta T C$ es el cambio en el tipo de cambio y $\Delta w$ es el cambio en salarios. El cuadro 1 muestra que la variabilidad resulta significativa en esta regresión y con coeficiente de largo plazo positivo. ${ }^{10}$

La regresión se estimó bajo dos especificaciones debido a que las variables significativas eran distintas al cambiar el orden en el que se eliminaban las no significativas. En el panel A se eliminaron primeramente términos distintos a la variabilidad, mientras que en el panel B se prescindió al principio de términos distintos a la oferta monetaria. De esta forma, se tiene una especificación que pone mayor énfasis en la variabilidad y otra que lo hace en factores tradicionales de inflación. En el cuadro 1 se aprecia que la variabilidad de precios relativos contribuye entre el $11.88 \%$ y el $9.45 \%$ al ajuste de la regresión.

9 Se presentan las regresiones utilizando al agregado monetario más significativo en el periodo, M3. Al sustituir con M2 y M1 se obtienen resultados muy similares, tanto en ajuste como en coeficientes.

10 Otros trabajos han refinado el argumento de la variabilidad de precios controlados, mencionando que de existir inflexibilidad a la baja en los otros precios, la función de densidad de precios mostraría un sesgo positivo. La contribución del sesgo de la distribución en la regresión es positiva y significativa cuando se utiliza en lugar de la variabilidad de precios relativos o multiplicada por ésta, pero el ajuste de la regresión es menor que cuando se utiliza a la variabilidad, por lo que se ignora el sesgo de la distribución. 


\begin{tabular}{|c|c|c|c|}
\hline \multicolumn{4}{|l|}{$\begin{array}{|ll|}\text { Cuadro } 1 \text { PANEL A } \\
\end{array}$} \\
\hline \multicolumn{4}{|c|}{$\begin{array}{l}\text { Variable Dependiente: INF } \\
\text { Muestra: 1986:02 1996:11 }\end{array}$} \\
\hline Variable & Coeficiente & Estadístico-t & $\begin{array}{c}\text { Contribución } \\
\mathrm{a} \mathrm{R}^{2} \\
\end{array}$ \\
\hline$\overline{\mathrm{C}}$ & 0.000997 & 0.869240 & \\
\hline DM3(-4) & 0.079467 & 2.692435 & 5.25 \\
\hline DTC $(-1)$ & 0.072455 & 4.896624 & 12.51 \\
\hline DTC (-3) & 0.040792 & 2.739965 & \\
\hline $\operatorname{INF}(-1)$ & 0.656102 & 13.49971 & 58.41 \\
\hline DW & 0.103708 & 4.263387 & 9.61 \\
\hline $\mathrm{DW}(-1)$ & 0.031117 & 4.935286 & \\
\hline DW(-12) & -0.080489 & -3.231445 & \\
\hline VAREL & 1.055200 & 5.822757 & 11.88 \\
\hline VAREL(-1) & -0.489912 & -2.435902 & \\
\hline VAREL(-2) & -0.485854 & -2.841826 & \\
\hline VAREL(-11) & 0.423083 & 2.554337 & \\
\hline PR cuadrada & 0.916558 & "Durbin-Watson stad & 1.881846 \\
\hline $\mathrm{R}$ cuadrada ajustada & 0.908780 & R cuadrada sin VAREL: & 0.874319 \\
\hline \multicolumn{4}{|l|}{ Cuadro 1 PANEL B } \\
\hline \multicolumn{4}{|c|}{$\begin{array}{l}\text { Variable Dependiente: INF } \\
\text { Muestra: 1986:02 1996:11 }\end{array}$} \\
\hline Variable & Coeficiente & Estadístico-t & $\begin{array}{c}\text { Contribución } \\
\mathrm{a} \mathrm{R}^{2}\end{array}$ \\
\hline$\overline{\mathrm{C}}$ & 0.000663 & 0.535585 & \\
\hline DM3(-4) & 0.087740 & 2.860253 & 9.84 \\
\hline DM3(-8) & 0.033293 & 1.134884 & \\
\hline DTC $(-1)$ & 0.073190 & 4.720156 & 12.80 \\
\hline DTC (-3) & 0.033618 & 2.182947 & \\
\hline $\operatorname{INF}(-1)$ & 0.618901 & 12.08819 & 52.79 \\
\hline DW & 0.109898 & 4.259835 & 11.10 \\
\hline DW(-1) & 0.033448 & 5.113573 & \\
\hline DW $(-12)$ & -0.083587 & -3.175284 & \\
\hline VAREL(-1) & 1.118371 & 5.930110 & 9.45 \\
\hline $\operatorname{VAREL}(-3)$ & -0.581142 & -2.783204 & \\
\hline "R cuadrada & 0.907687 & " Durbin-Watson stad & 1.775775 \\
\hline $\mathrm{R}$ cuadrada ajustada & 0.899930 & R cuadrada sin VAREL: & 0.875561 \\
\hline
\end{tabular}

La contribución al ajuste de la regresión se puede hacer con base en la ecuación (5):

$$
R^{2}=\frac{b_{1} \sum_{t=1}^{N}\left(x_{1, t}-\overline{x_{1}}\right)\left(y_{t}-\bar{y}\right)+\ldots . .+b_{K} \sum_{t=1}^{N}\left(x_{K, t}-\overline{x_{K}}\right)\left(y_{t}-\bar{y}\right)}{\sum_{t=1}^{N}\left(y_{t}-\bar{y}\right)^{2}}
$$


La $R^{2}$ es igual a la suma de los coeficientes de la regresión por la covarianza con la variable dependiente que tenga cada variable exógena, entre la varianza de la variable dependiente. Así, la contribución de cada sumando representa una medida de la contribución de cada variable al ajuste de la regresión. Este procedimiento resulta indicativo en este contexto, puesto que todas las variables en el largo plazo contribuyen positivamente a la inflación. ${ }^{11}$

Como se puede apreciar en la gráfica 1, la variabilidad de precios más asociada a la inflación es la de los bienes administrados. Por lo explicado en la parte teórica, esta relación podría deberse a que el aumento en precios (inflación) genera un aumento en la variabilidad, en lugar de que la variabilidad cause a la inflación. Para controlar por este problema de endogeneidad, el cuadro 2, panel A, presenta la regresión de la inflación contra la variabilidad de precios libres solamente. En dicha regresión se confirma la hipótesis de que la inflación causa a la variabilidad de precios relativos, como lo sugiere la teoría tradicional, si bien la contribución de la variabilidad se reduce al 3.37\%. Con el propósito de establecer si la hipótesis contraria también se sostiene empíricamente, se presenta el ejercicio del panel B, en el que se ve el efecto de la variabilidad de precios administrados, que probablemente no es causada por la inflación mensual por ser consecuencia de decisiones administrativas, sobre la inflación de bienes libres. Los resultados son similares a los del panel A, en el que se tiene una contribución a la inflación significativa, y esta contribución es menor al $4 \% .^{12}$

\begin{tabular}{||cccc||}
\hline Cuadro 2 PANEL A & & & \\
\hline \hline Variable Dependiente: INF & & & \\
Muestra: 1986:02 1996:11 & Coeficiente & Estadístico-t & $\begin{array}{c}\text { Contribución } \\
\text { a R }\end{array}$ \\
\hline \hline Variable & & & 6.05 \\
& 0.000219 & 0.147885 & 13.80 \\
C & 0.084848 & 2.503308 & 65.60 \\
DTC(-1) & 0.078986 & 4.675059 & 11.18 \\
DTC(-3) & 0.038971 & 2.295849 & \\
INF(-1) & 0.653629 & 11.53979 & 3.37 \\
DW & 0.111715 & 3.914351 & \\
DW(-1) & 0.034629 & 4.695516 & 1.825411 \\
DW(-12) & -0.087036 & -2.982952 & 0.874319 \\
VARNAD & 0.741752 & 1.660390 & \\
VARNAD(-1) & -1.061870 & -2.501374 & \\
VARNAD(-11) & 0.998249 & 2.626067 & \\
\hline \hline R cuadrada & 0.889312 & Durbin-Watson stad & \\
R cuadrada ajustada & 0.880011 & R cuadrada sin VARNAD. & \\
\hline \hline Cuadro 2 PANEL B & & & \\
\end{tabular}

${ }^{11}$ El problema con este procedimiento es que algunos de los factores de estas variables tendrán signos negativos cuando el coeficiente de correlación sea negativo y la covarianza positiva o viceversa, lo que apegándonos a la interpretación presentada, equivaldría a que la contribución a la explicación fuera negativa, lo que no tiene ningún sentido. Para subsanar tal deficiencia, se utiliza el concepto de contribución incremental a la explicación o ajuste de la regresión. La interpretación de este concepto se explica más adelante.

12 Debido a lo similar que resultan ambas medidas de variabilidad, el resto de las pruebas se hace con la varianza de Theil. 


\begin{tabular}{||cccc||}
\hline $\begin{array}{l}\text { Variable Dependiente: INFNAD } \\
\text { Muestra: 1986:03 1996:11 }\end{array}$ & Coeficiente & Estadístico-t & $\begin{array}{c}\text { Contribución } \\
\text { a R }\end{array}$ \\
\hline \hline Variable & 0.000530 & 0.567605 & \\
& 0.051715 & 1.781933 & 7.60 \\
DM3(-2) & 0.044142 & 1.750701 & 11.18 \\
DM3(-4) & 0.076118 & 6.437654 & 69.74 \\
DTC(-1) & 0.022134 & 1.785746 & 8.27 \\
DTC(-3) & 0.714961 & 15.07871 & \\
INFNAD(-1) & 0.086083 & 4.417774 & 3.24 \\
DW & 0.028248 & 5.352698 & \\
DW(-1) & -0.068345 & -3.458847 & \\
DW(-12) & 0.466356 & 3.115181 & \\
VARAD & -0.492231 & -3.212594 & \\
VARAD(-2) & -0.262869 & -1.940395 & 2.081126 \\
VARAD(-6) & 0.330216 & 2.465640 & 0.921042 \\
VARAD(-11) & 0.242556 & 1.930402 & \\
VARAD(-13) & 0.941439 & Durbin-Watson stad & \\
\hline \hline R cuadrada & 0.934819 & R cuadrada sin VARAD. & \\
R cuadrada ajustada & & &
\end{tabular}

El ejercicio del panel B corrobora la hipótesis de que la variabilidad en precios relativos producida por aumentos en precios administrados provoca aumentos generalizados de precios. Una prueba de causalidad de Granger entre la variabilidad en precios administrados y no administrados muestra que es precisamente la variabilidad de los bienes administrados la que precede a la de los bienes libres -mientras que lo contrario no sucede (cuadro 3, panel A)-. Esto se interpreta como que la variabilidad en precios administrados causa a la variabilidad en precios libres, la cual a su vez está asociada con una mayor inflación.

El procedimiento a seguir cuando se tiene un problema de endogeneidad es encontrar un instrumento que esté correlacionado con la variable que se considera exógena o explicativa y que no pueda ser causado por la variable endógena o explicada. En el caso presente, se cuenta con una variable que satisface estos requerimientos. Asimismo, como se ha sostenido a lo largo del documento, los precios administrados tendían a aumentar durante la época de los Pactos a raíz de las concertaciones de precios entre los sectores participantes. Por otra parte, las concertaciones en general no eran causadas por mayores niveles de inflación sino que se convocaban por dos motivos: 1) cuando era necesario hacer algún ajuste en las políticas acordadas o, 2) cuando se terminaba una etapa del Pacto. Por ello, se construye una variable dummy que registra un valor de 1 únicamente en el mes en el que se implementó una etapa más del Pacto. En el cuadro 4 se presenta la regresión que contiene esta dummy en la ecuación que explica a la inflación con crecimiento en agregados monetarios, en tipo de cambio, en salarios y con inflaciones rezagadas. Como se puede apreciar, esta variable tiene el signo esperado y es significativa al $90 \%$ de confianza, lo que indica que la variabilidad de precios relativos causa a la inflación. ${ }^{13}$

\footnotetext{
${ }^{13}$ También se construye otra dummy para el mes en el que se anunció una nueva concertación del Pacto. Esta variable muestra resultados muy similares en coeficiente y significancia a los de la dummy de implementación para el periodo 1992-1996, en el que los precios administrados sirvieron como "señal de inflación futura", como se muestra más adelante. Cuando se hace la prueba para toda la muestra, la variable de anuncio registra un coeficiente no significativo.
} 


\section{Cuadro 3 PANEL A}

Prueba de Causalidad de Granger

Muestra: 1985:01 1996:12 Rezagos: 2

\begin{tabular}{|c|c|c|c|}
\hline Hipótesis Nula & Obs. & Estadístico F & Probabilidad \\
\hline VARNAD no causa VARAD & 141 & 1.20235 & 0.30366 \\
\hline VARAD no causa VARNAD & & 23.6200 & $1.6 \mathrm{E}-09$ \\
\hline \multicolumn{4}{|l|}{\begin{tabular}{|l|l|} 
Cuadro 3 PANEL B \\
\end{tabular}} \\
\hline \multicolumn{4}{|c|}{\begin{tabular}{|l|} 
Prueba de Causalidad de Granger \\
Muestra: 1985:01 1991:12 Rez
\end{tabular}} \\
\hline Hipótesis Nula & Obs. & Estadístico F & Probabilidad \\
\hline $\begin{array}{l}\text { VARNAD no causa VARAD } \\
\text { VARAD no causa VARNAD }\end{array}$ & 79 & $\begin{array}{l}0.62971 \\
7.09767\end{array}$ & $\begin{array}{l}0.64292 \\
7.4 \mathrm{E}-05\end{array}$ \\
\hline \multicolumn{4}{|l|}{\begin{tabular}{|l} 
Cuadro 3 PANEL $\mathrm{C}$ \\
\end{tabular}} \\
\hline \multicolumn{4}{|l|}{$\begin{array}{l}\text { Prueba de Causalidad de Granger } \\
\text { Muestra: 1992:01 1996:12 Rez }\end{array}$} \\
\hline $\begin{array}{l}\text { Hipótesis Nula } \\
\end{array}$ & Obs. & Estadístico F & Probabilidad \\
\hline \begin{tabular}{|l|} 
VARNAD no causa VARAD \\
VARAD no causa VARNAD \\
\end{tabular} & 60 & $\begin{array}{l}0.74169 \\
0.57542 \\
\end{array}$ & $\begin{array}{l}0.56802 \\
0.68171 \\
\end{array}$ \\
\hline
\end{tabular}

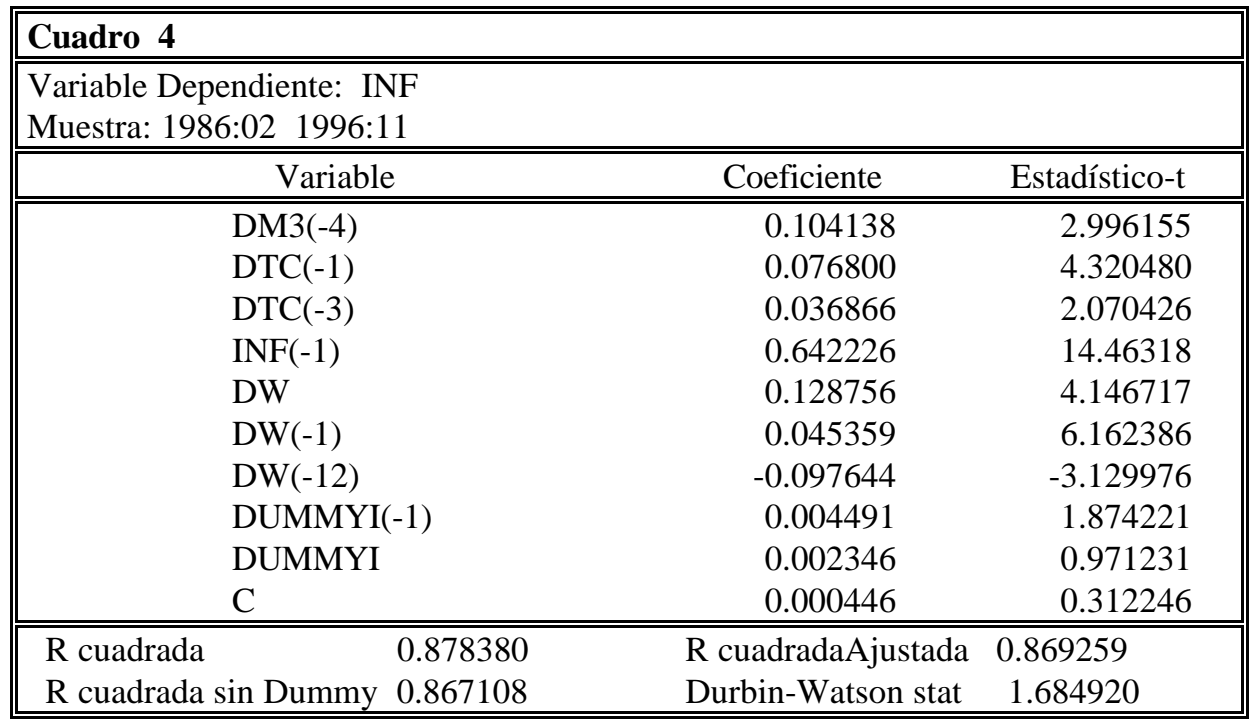

En la gráfica 1 se puede apreciar que la variabilidad de precios (en particular la de los administrados) disminuye considerablemente a partir de 1992, reducción que se debió a los dos factores mencionados anteriormente: primero, los precios de los bienes proveídos por el sector público iniciaron una política de aumentos mensuales conforme a la inflación prevista. Estos aumentos mensuales eran anunciados anticipadamente. Esta política contribuyó a que disminuyeran las divergencias entre los precios públicos y el resto de los precios. Segundo, se inició la política de liberalización de precios de bienes producidos por el sector privado. En 1992 la mayor parte de los precios se "flexibilizaron", es decir, se dejaron a la determinación de los productores pero bajo observación gubernamental, mientras que en 1993 se liberalizó por 
completo la mayor parte de estos bienes. De esta forma, los precios administrados pasaron de constituir el $36 \%$ del gasto de los consumidores a ser el $16 \%$ en la actualidad.

Estos cambios modificaron significativamente la variabilidad de precios administrados como se ve en la gráfica 1, pero además implicaron que los precios administrados dejaran de adelantarse a la variabilidad de los precios libres. El panel $\mathrm{C}$ del cuadro 3 muestra que a partir de 1992 no hay causalidad de Granger entre las variabilidades de los dos grupos de bienes. De hecho, en las regresiones del cuadro 1 se detecta un cambio estructural en enero de 1992. El cuadro 5, páneles A y B, muestra los cambios en los coeficientes de las variables de la regresión. En particular, las variabilidades de precios relativos que resultan significativas son siempre positivas antes de 1992, mientras que para el periodo posterior prácticamente se cancelan. La contribución de la variabilidad al ajuste de la regresión disminuye entre los dos periodos (pasa de contribuir con un $4 \%$ a un $2.3 \%$ al ajuste de la regresión).

En resumen, la variabilidad de precios relativos producida por los precios administrados resulta un factor significativo para explicar la inflación mensual. Esta variabilidad de precios y su influencia sobre la inflación han disminuido considerablemente desde 1992, por lo que podría pensarse que el papel de los precios administrados sobre la inflación es menor en el presente. Sin embargo, al disminuir la discrecionalidad en la determinación de los precios administrados con el anuncio anticipado de sus aumentos, el impacto sobre el incremento en el resto de los precios ha aumentado.

\begin{tabular}{|c|c|c|c|}
\hline Cuadro 5 PANEL A & & & \\
\hline $\begin{array}{l}\text { Variable Dependiente: } \\
\text { Muestra: 1986:02 } 1991\end{array}$ & & & \\
\hline Variable & " Coeficiente & Estadístico-t & \\
\hline$\overline{\bar{C}}$ & "-3.97E-05 & $=0.015596$ & \\
\hline DM3(-4) & 0.101510 & 2.336175 & \\
\hline DTC $(-1)$ & 0.166422 & 3.573263 & \\
\hline DTC $(-3)$ & 0.002757 & 0.063249 & \\
\hline $\operatorname{INF}(-1)$ & 0.504861 & 6.466738 & \\
\hline DW & 0.112134 & 3.364395 & \\
\hline DW(-1) & 0.050993 & 4.746041 & \\
\hline DW $(-12)$ & -0.073156 & -2.153459 & \\
\hline VAR & 2.159591 & 4.546261 & \\
\hline $\operatorname{VAR}(-1)$ & -0.580707 & -1.016173 & \\
\hline VAR(-2) & -0.745241 & -1.634760 & \\
\hline VAR(-11) & 0.698773 & 1.779699 & \\
\hline R cuadrada & 0.930957 & Durbin-Watson stad & 1.934316 \\
\hline$R$ cuadrada ajustada & 0.918084 & R cuadrada sin VAR. & 0.894093 \\
\hline
\end{tabular}




\begin{tabular}{|c|c|c|c|}
\hline Cuadro 5 PANEL B & & & \\
\hline $\begin{array}{l}\text { Variable Dependiente: } \\
\text { Muestra: 1992:01 } 199\end{array}$ & & & \\
\hline Variable & בCoeficiente & Estadís & \\
\hline$\overline{\mathrm{C}}$ & 0.000726 & 0.49 & \\
\hline DM3(-4) & 0.062171 & 2.52 & \\
\hline DTC $(-1)$ & 0.063097 & 7.75 & \\
\hline DTC (-3) & 0.028529 & 3.17 & \\
\hline $\operatorname{INF}(-1)$ & 0.799105 & 16.2 & \\
\hline DW & 0.029667 & 0.88 & \\
\hline DW $(-1)$ & 0.009631 & 2.32 & \\
\hline DW(-12) & -0.021973 & -0.64 & \\
\hline VAR & 2.952005 & 3.18 & \\
\hline $\operatorname{VAR}(-1)$ & -0.640982 & -0.69 & \\
\hline VAR(-2) & -2.205768 & -2.79 & \\
\hline $\operatorname{VAR}(-11)$ & -0.436182 & -0.62 & \\
\hline R cuadrada & 0.940116 & "Durbin-Watson stad & 2.207711 \\
\hline $\mathrm{R}$ cuadrada ajustada & 0.926100 & R cuadrada sin VAR. & 0.918317 \\
\hline
\end{tabular}

\section{SEÑAL DE PRECIOS ADMINISTRADOS SOBRE LA INFLACION}

Como consecuencia de la reducción en el número de precios administrados y la forma en que se modifican los precios públicos, es posible anticipar el aumento en los precios de los bienes administrados. Por ello, los incrementos en los precios libres pueden incorporar este aumento aún antes de que éste ocurra, fenómeno que no se presentaba antes de 1992. El cuadro 6 muestra a la inflación en bienes no administrados anticipándose a la de los administrados para este segundo periodo.

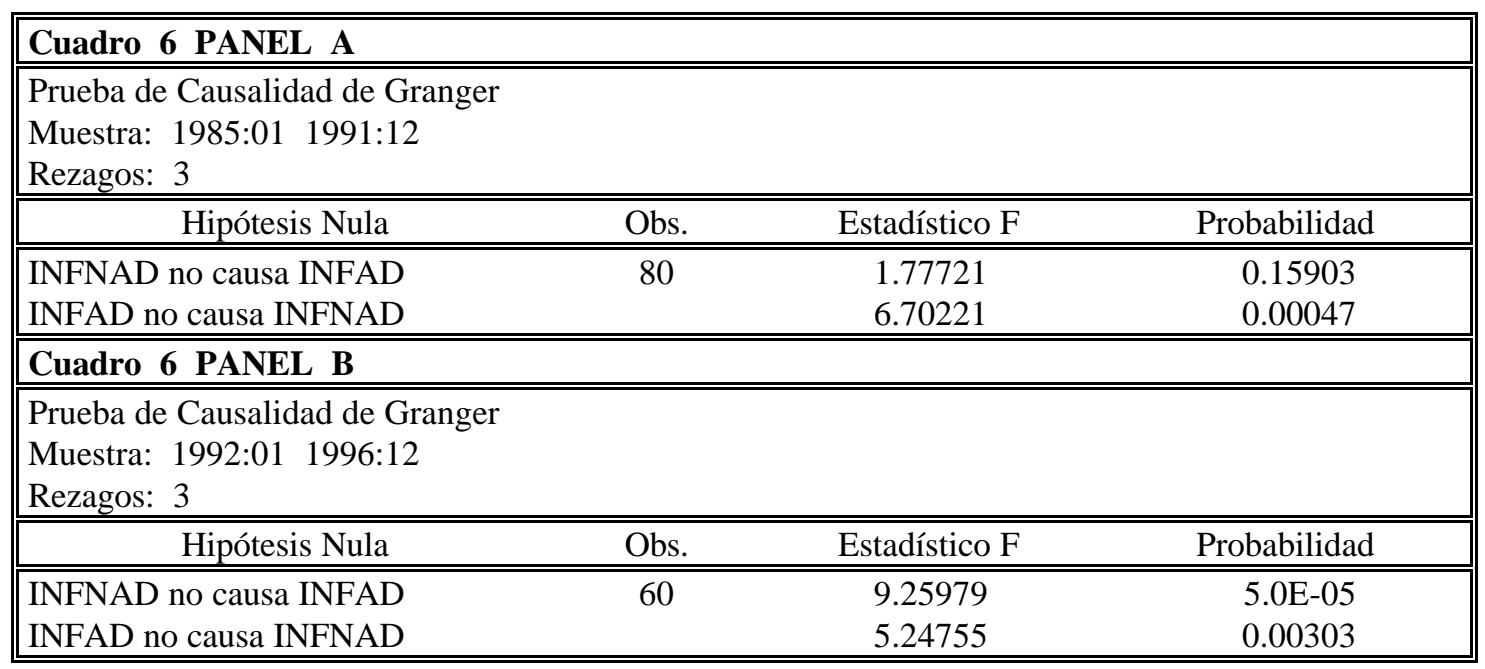

Al ser los cambios en los precios públicos más previsibles, los agentes privados se anticipan a ellos al ajustar sus precios (cuadro 6, páneles B y D). Esto significa que los cambios 
en los precios administrados proveen información al público sobre el nivel de precios que se presentará en el futuro. El anuncio del precio al que se venderá el bien y su tasa de ajuste mensual modifica (o confirma) las expectativas que los agentes tienen de la inflación futura.

\begin{tabular}{||lccc||}
\hline Cuadro 6 PANEL C & & \\
\hline \hline Prueba de Causalidad de Granger \\
Muestra: $1985: 01 \quad 1991: 12$ & & & \\
Rezagos: 9 & & & \\
\hline \hline Hipótesis Nula & Obs. & Estadístico F & Probabilidad \\
\hline \hline INFNAD no causa INFAD & 74 & 1.42902 & 0.19861 \\
INFAD no causa INFNAD & & 4.33362 & 0.00027 \\
\hline \hline Cuadro 6 PANEL D & & & \\
\hline \hline Prueba de Causalidad de Granger & & & \\
Muestra: 1992:01 1996:12 & & & \\
Rezagos: 9 & Obs. & 3.06323 & 0.00673 \\
\hline \hline \multicolumn{1}{|l}{ Hipótesis Nula } & 60 & 1.73512 & 0.11180 \\
\hline \hline INFNAD no causa INFAD & & & \\
INFAD no causa INFNAD & & & \\
\hline
\end{tabular}

El efecto de los aumentos en los bienes administrados sobre la inflación se puede ver agregando al efecto directo que éstos tienen como integrantes de la canasta de consumo el impacto del cambio en estos precios sobre la inflación de los bienes no administrados. Este impacto de los bienes no administrados se analiza con una regresión que incorpora, como las anteriores, el rezago de la inflación en bienes no administrados, cambios en oferta monetaria, en los salarios y en tipo de cambio, además de la inflación en bienes controlados. ${ }^{14}$ El cuadro 7 muestra que los cambios en los precios administrados tienen un impacto considerablemente mayor después de 1992 (panel B) que en el periodo previo (panel A), pese a que en la actualidad los bienes administrados tienen una ponderación en el gasto menor en 20 puntos porcentuales. El aumento de $1 \%$ en la canasta de bienes administrados se ve reflejado en un aumento del $33 \%$ en los precios libres, mientras que en el periodo previo el aumento era de sólo el $13 \% .^{15}$

La prueba presentada en el cuadro 7 podría estar sesgada debido a la reducción en el número de bienes administrados que se presentó en este periodo. Esto es, en el pasado los aumentos en la canasta de bienes con precios administrados tenían un impacto distinto sobre la canasta de bienes libres, debido a que el número de los bienes que la componían era menor. Para poder estimar este efecto sin que la prueba se afecte por la disminución en el número de bienes

${ }^{14}$ La ecuación estimada puede provenir de que los precios se ajustan parcialmente con respecto a los costos de producción, cuyos aumentos están determinados por costos de insumos importados, salarios, precios administrados e insumos domésticos, cuyo precio crece con la oferta monetaria doméstica. El rezago de inflación se debería a la relación que guardan los precios de hoy con los de ayer.

${ }^{15}$ Cabe señalar que de provenir la especificación analizada de una ecuación de ajuste parcial como la referida en el pié de página anterior, la estimación mostraría autocorrelación negativa, debido a que el error tiene una estructura MA(1). De hecho, las regresiones mostradas indican que se presenta la autocorrelación negativa. Modelando el término de error como un MA(1), se corrige la autocorrelación. Como los resultados son muy similares, cualitativa y cuantitativamente, bajo esta especificación a los aquí presentados, se optó por presentar la versión más sencilla. 
controlados, se consideró también el impacto de una canasta de bienes controlados durante todo el periodo sobre la de los bienes que estuvieron libres durante toda la muestra. El resultado es cualitativamente similar al del cuadro 7, si bien el coeficiente de los precios administrados sobre la inflación es apenas estadísticamente superior después de 1992, al pasar del $12.6 \%$ al 16.9\%. Por su parte, la contribución de los precios administrados al ajuste de la regresión pasa de ser el $3.47 \%$, en el periodo 1985-1991, al 8.04\% en el periodo 1992-1996.

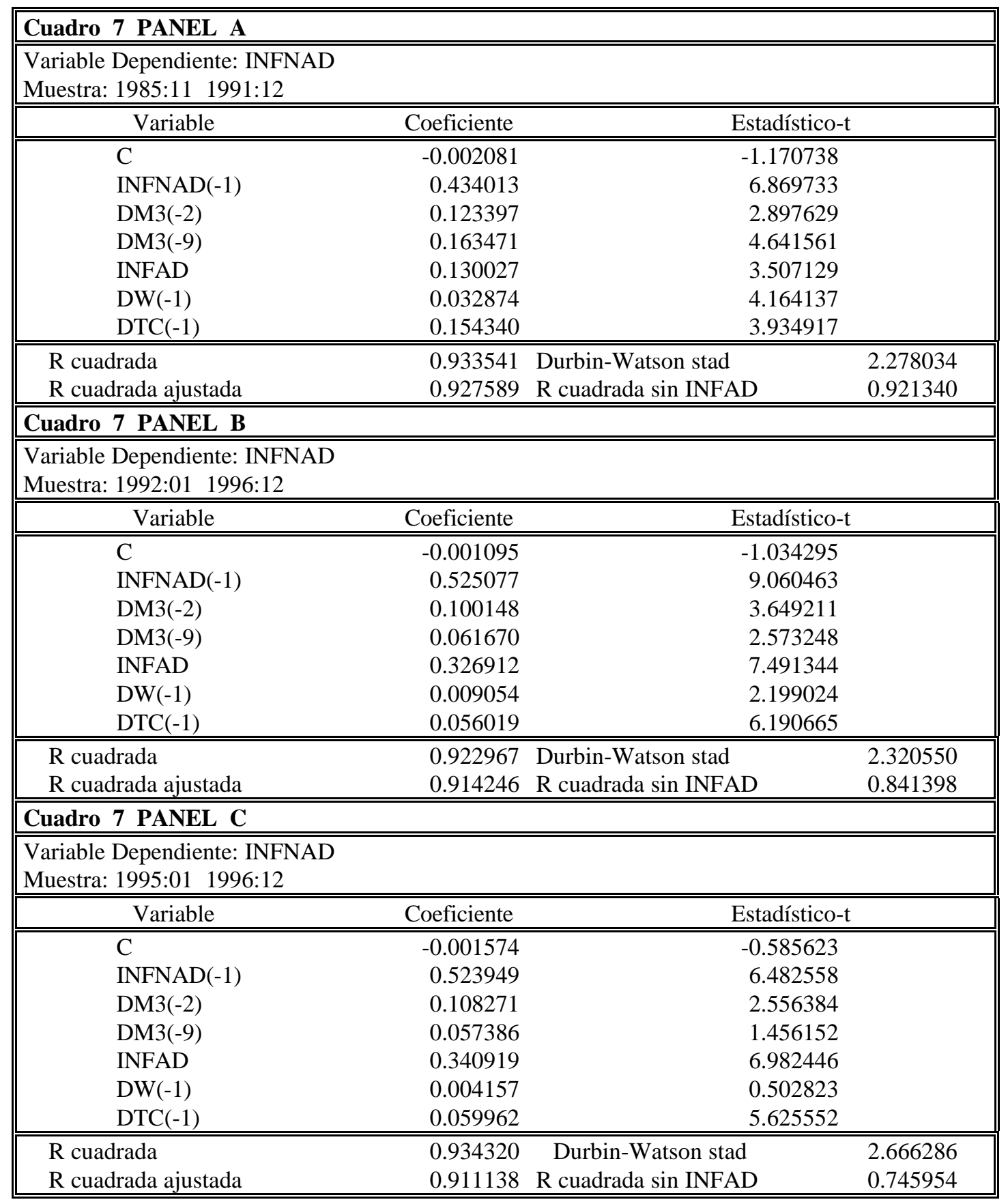

El mayor impacto de los bienes administrados sobre el aumento en los precios libres se debe a la nueva política de aumentos en precios administrados que entró en vigor en 1992. Al 
ser estos aumentos públicamente anunciados con anticipación, los agentes fijan sus precios de acuerdo con estos anuncios. De esta forma, tanto el ajuste en el nivel real al inicio de cada etapa de concertación como la tasa mensual de desliz del precio terminan afectando al nivel de precios. El resultado es que los precios administrados influyen de manera importante sobre el proceso de ajuste de los precios libres. Esto es, los aumentos en precios administrados aportan en la actualidad mayor información para explicar la inflación en precios libres.

La información adicional que una variable independiente puede contribuir a la explicación de una variable dependiente se puede medir con el cambio que presenta la $R^{2}$ al agregar dicha variable independiente a la regresión. En este caso, al quitar la inflación controlada de la regresión del panel A del cuadro 7, la $R^{2}$ cae apenas en un $1.32 \%$. Es decir, en el periodo previo a 1992, la inflación de bienes controlados contribuía con un poco más del $1 \%$ a la explicación de la inflación en bienes no administrados. Esta influencia es mucho mayor durante el periodo posterior a 1992, en el que la $R^{2}$ sin la inflación de bienes controlados en la regresión del panel B caería en un $9.69 \%$. Esto es, el cambio en los precios administrados provee el $10 \%$ de la información para poder predecir el cambio en los bienes libres. Como se mencionó anteriormente, la contribución al ajuste de la regresión es similar cuando se hace la evaluación considerando un posible sesgo de contar con un número menor de bienes controlados durante el segundo periodo.

Estadísticamente, la mayor importancia de los precios administrados se debe a que en el periodo posterior a 1992 los precios administrados tuvieron aumentos que fueron más independientes de las otras variables que explican la inflación y por tanto brindaron a los agentes más información acerca del proceso inflacionario. Esto se debió en alguna medida a que los precios administrados aumentaban mensualmente conforme a la inflación esperada y este comportamiento es más regular que el libre movimiento de las otras variables que afectan el alza de precios. Probablemente, una causa más significativa de este comportamiento más independiente son las alzas en los niveles reales que durante este periodo se han registrado en algunos de estos precios. Por ello, los precios administrados, a pesar de ser un número más reducido, son hoy en día más importantes para explicar los aumentos en el nivel general de precios. La guía que estos precios provee al resto de los mismos hace más importante el que se eviten ajustes bruscos en los aumentos en estos bienes, guardando una relación estrecha con sus costos y/o determinando sus aumentos de forma consistente con el pronóstico de inflación del Banco de México.

El aumento en información adicional para explicar la inflación de bienes libres proveída por los precios administrados es mayor con la inclusión del periodo de alzas en niveles reales; en el periodo enero de 1995 a diciembre de 1996, los precios administrados brindaron $25.25 \%$ de la información del comportamiento de los precios libres (panel C). Como se puede observar, las $R^{2}$ de las regresiones que incluyen todos los factores son muy similares en los tres periodos, lo que indica que en el periodo previo los aumentos en precios administrados seguían procesos de ajuste muy similares a los aumentos en tipo de cambio y salarios, mientras que en el periodo posterior se registra un patrón de ajustes más independiente por parte de los precios administrados y estos aumentos impactan en mayor medida a los aumentos en precios libres.

Cabe hacer la aclaración que esta mayor independencia no se ha debido a los trastornos ocurridos a consecuencia del brote inflacionario de 1995. Se podría pensar que se perdió la 
relación existente entre los canales tradicionales de inflación y los precios administrados y que este desarreglo sea la causa del aumento en la contribución al ajuste de la regresión de estos precios. Sin embargo, un desarreglo en precios relativos de mayor magnitud fue causado al lanzar el plan de estabilización de 1987, como se puede ver en la gráfica 1; en dicha ocasión no se tuvo el mismo efecto de precios administrados sobre libres. En todo caso sería recomendable revisar este resultado cuando se hayan acumulado más observaciones, para poder así distinguir entre estas dos hipótesis.

Combinando las variables utilizadas previamente en un vector autorregresivo (VAR) se puede comprobar que la inflación en bienes administrados en el periodo 1992 a 1996 tiene una influencia mayor sobre la variabilidad de la inflación de los bienes no administrados que para el periodo previo y que este mayor impacto no se debe al comportamiento de las otras variables. ${ }^{16}$ Se estiman las regresiones entre cada una de las variables del vector y los rezagos de las demás variables del vector, pero no se presentan las estimaciones por no aportar directamente información relevante para el presente análisis. ${ }^{17}$

Con las estimaciones se puede proceder a obtener la descomposición de la varianza de la inflación de bienes no administrados. El orden en que se presentan las series es importante para esta descomposición, puesto que la correlación existente entre dos variables (que contribuye a que se tenga una mayor varianza) se atribuye a la que se especifica con anterioridad. Dado que el aumento en el precio de los bienes administrados obedece en gran medida a aumentos en las variables tradicionales que explican a la inflación y debido a que el propósito del trabajo es determinar la importancia de los precios administrados en la inflación sin exagerar su efecto sobre bienes no administrados, en el ordenamiento se asigna al aumento en bienes no administrados un lugar posterior al de las variables tradicionales y antes solamente de los aumentos en bienes no administrados.

El cuadro 8 presenta los resultados de esta descomposición para los dos periodos de interés. De esta forma se obtiene que la inflación de bienes administrados contribuye con menos del 2\% a la explicación de la varianza de la inflación de bienes no administrados durante el periodo de 1985 a 1991, mientras que su contribución asciende a un rango que va de un 18 a un 40\% para el periodo de 1992 a 1996.

El cambio en la política de aumento de precios administrados es el principal responsable de este aumento en la contribución de precios administrados a la inflación, junto con el aumento en el nivel real de los precios administrados. Entre diciembre de 1988 y diciembre de 1991 hubo un periodo similar de aumentos de precios administrados, en el cual la contribución de los bienes administrados a la varianza de los precios no administrados estuvo en el rango del 18 y $29 \% .^{18}$ Aunque esta contribución es importante resulta menor al rango del 24 al 38\% registrado durante el periodo de aumentos bajo la nueva política, que va de julio de 1995 a diciembre de 1996. Por

\footnotetext{
${ }^{16}$ Una buen tratamiento del tema VAR se presenta en Hamilton (1994), capítulo 11.

${ }^{17}$ Una ventaja de la estimación del VAR es que realiza la corrección más comúnmente utilizada cuando hay un problema de endogeneidad: el utilizar como instrumentos rezagos de las variables.

18 Como se mencionó anteriormente, durante el año de 1989 los precios administrados permanecieron prácticamente fijos, en la muestra referida se tuvo que incluir este periodo debido a que de diciembre de 1989 a diciembre de 1991 no se tiene suficiente número de observaciones para la estimación del VAR.
} 
otra parte, el periodo en el que no se dieron aumentos sensibles en precios reales en los precios administrados, de 1985 a octubre de 1987, se vio una contribución a la varianza del orden del 5 y $2 \%$, mientras que el periodo en que no se dieron aumentos en precios reales, de enero de 1992 a marzo de 1995, se registró una contribución a la varianza en el rango del 34 y $15 \%$.

\begin{tabular}{|c|c|c|c|c|c|c|}
\hline \multicolumn{7}{|c|}{\begin{tabular}{|l} 
Cuadro 8 PANEL A \\
\end{tabular}} \\
\hline \multicolumn{7}{|c|}{$\begin{array}{l}\text { Descomposición de la Varianza de INFNAD } \\
\text { Muestra 1985:02-1991:12 }\end{array}$} \\
\hline PERIODO & E.S & DTC & DW & INFAD & INFNAD & DM3 \\
\hline 1 & 0.033391 & 10.84510 & 5.269979 & 0.819424 & 75.35947 & 7.706028 \\
\hline 2 & 0.035632 & 25.42705 & 15.49704 & 1.669517 & 29.89201 & 27.51439 \\
\hline 3 & 0.037676 & 32.02944 & 12.00750 & 1.642866 & 24.90652 & 29.41368 \\
\hline 4 & 0.038441 & 37.11607 & 9.900510 & 1.870895 & 21.22648 & 29.88604 \\
\hline 5 & 0.039155 & 40.00649 & 8.636858 & 1.840733 & 18.54330 & 30.97263 \\
\hline 6 & 0.039605 & 42.69125 & 7.671391 & 1.716335 & 16.59771 & 31.32331 \\
\hline 7 & 0.039992 & 44.69794 & 6.957689 & 1.639656 & 15.16173 & 31.54298 \\
\hline 8 & 0.040308 & 46.24942 & 6.464940 & 1.602796 & 14.09425 & 31.58860 \\
\hline 9 & 0.040563 & 47.50627 & 6.084422 & 1.577592 & 13.30728 & 31.52444 \\
\hline 10 & 0.040777 & 48.47546 & 5.790928 & 1.560867 & 12.69847 & 31.47427 \\
\hline \multicolumn{7}{|c|}{ ORDEN: DM3 DTC DW INFAD INFNAD } \\
\hline \multicolumn{7}{|c|}{ Cuadro 8 PANEL B } \\
\hline \multicolumn{7}{|c|}{$\begin{array}{l}\text { Descomposición de la Varianza de INFNAD } \\
\text { Muestra 1992:01-1996:12 }\end{array}$} \\
\hline PERIODO & S.E & DTC & $\overline{\mathrm{DW}}$ & INFAD & INFNAD & DM3 \\
\hline 1 & 0.062508 & 0.008943 & 3.741978 & 38.28755 & 57.43543 & 0.526095 \\
\hline 2 & 0.064004 & 24.45953 & 2.552049 & 32.88289 & 20.93852 & 19.16701 \\
\hline 3 & 0.065113 & 33.01001 & 1.601297 & 25.41117 & 19.67914 & 20.29839 \\
\hline 4 & 0.065552 & 37.87822 & 1.371091 & 21.61661 & 18.99655 & 20.13752 \\
\hline 5 & 0.066321 & 39.14481 & 1.255780 & 19.28667 & 17.22391 & 23.08883 \\
\hline 6 & 0.066364 & 40.08751 & 1.175603 & 18.60990 & 16.57528 & 23.55171 \\
\hline 7 & 0.066418 & 40.53815 & 1.179735 & 18.38353 & 16.35046 & 23.54813 \\
\hline 8 & 0.066493 & 40.60793 & 1.161552 & 18.20826 & 16.25125 & 23.77101 \\
\hline 9 & 0.066499 & 40.67161 & 1.153679 & 18.12953 & 16.20411 & 23.84107 \\
\hline 10 & 0.066506 & 40.70952 & 1.151634 & 18.09695 & 16.17547 & 23.86643 \\
\hline \multicolumn{7}{|c|}{ ORDEN: DM3 DTC DW INFCON INFNCON } \\
\hline
\end{tabular}

Al ajustar precios mediante anuncios públicos y anticipados, la contribución de los precios administrados al aumento en el resto de los precios es más fuerte y significativa. Por ello, al aumentar los precios públicos de forma inesperada (por ejemplo, cuando se presentaron aumentos reales) durante el periodo 1992 a 1996, se registra un aumento perceptible en el coeficiente con el cual el aumento de precios administrados afecta a los aumentos en precios libres. Los valores estimados del VAR se pueden utilizar para obtener las funciones impulso respuesta de las variables que forman al vector sobre el aumento en precios de bienes no administrados.

La gráfica 4 muestra la respuesta que se obtiene del sistema estimado sobre la inflación en bienes no administrados cuando se presenta una perturbación de $1 \%$ en cada una de las variables en el periodo cero. La línea continua denota la trayectoria estimada y las líneas punteadas muestran los intervalos de confianza en más/menos dos desviaciones estándar. De la comparación entre 1985-1991 y 1992-1996 destacan tres aspectos. Primero, se disipa más 
rápido el efecto de una perturbación en las variables del sistema sobre la inflación de bienes libres en el segundo periodo. De esta forma un aumento, por ejemplo, en el tipo de cambio deja de tener efecto en la inflación en un menor número de periodos en 1992-1996 que en 19851991. Segundo, los precios administrados, después de incrementar la inflación en bienes libres durante los primeros periodos, presentan una reversión para tener un impacto negativo después de unos meses en el primer periodo. Esto se explica porque los aumentos se presentaban en un periodo solamente y después el precio no cambiaba por varios meses, es decir, la inflación provocada por los precios administrados se compensaba parcialmente con menores inflaciones en los meses siguientes si no se presentaban nuevos aumentos, lo que no ocurre en el segundo periodo. Tercero, como en el cuadro 7, aquí también se puede apreciar que el efecto de los bienes administrados sobre la inflación es mayor en el periodo 1992-1996 que en 1985-1991. La magnitud prácticamente se duplica y el valor es significativamente distinto de cero para los tres primeros meses, después de un aumento inesperado en precios administrados durante 19921996.

\section{Gráfica 4}

Funciones de impulso respuesta para 1985 a 1991

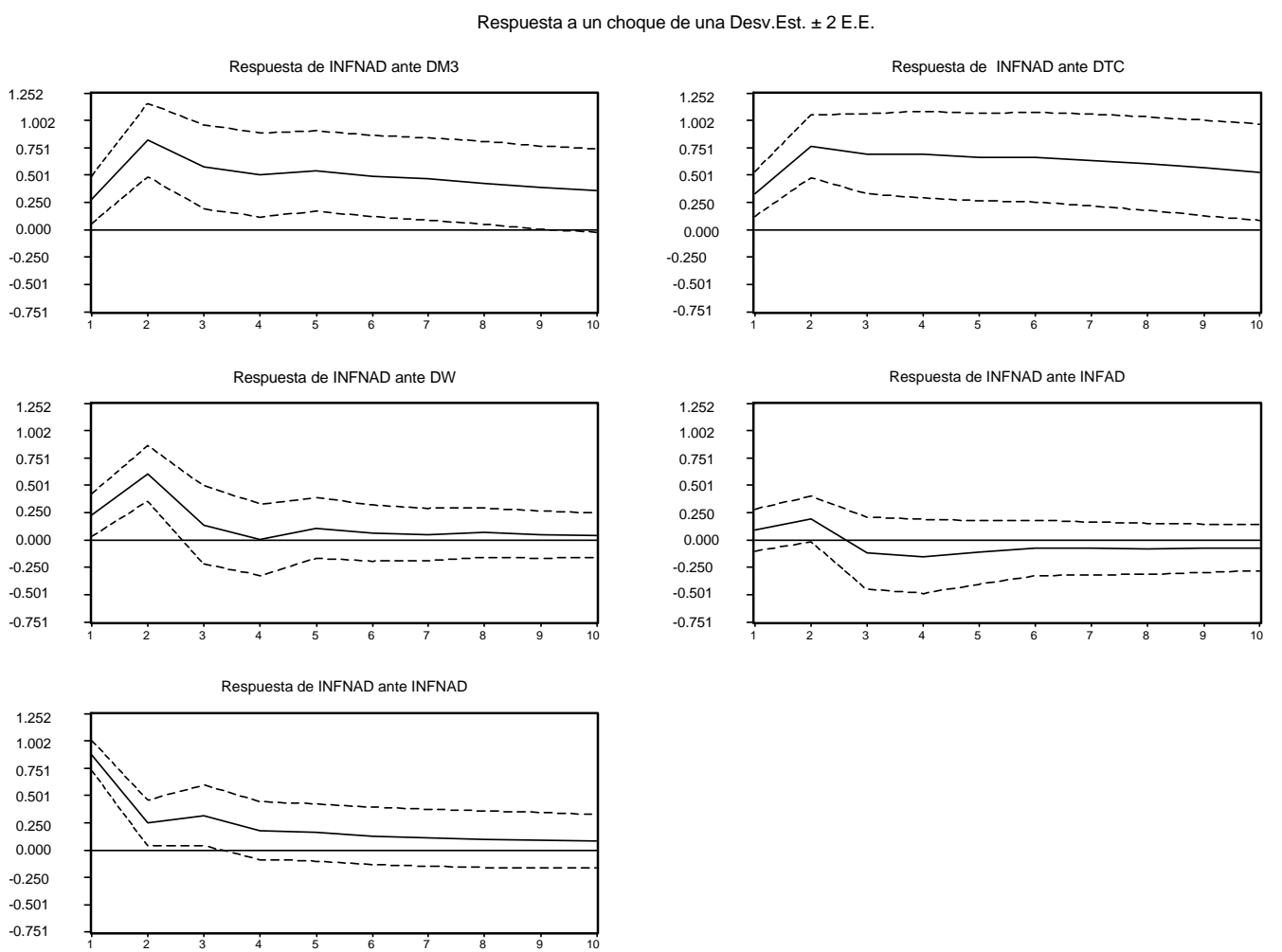

Estos resultados implican que los aumentos para recuperar el precio real de los bienes administrados tienen un impacto significativo y considerable sobre la inflación mensual por un periodo de hasta tres meses, lo que sin duda tiene un efecto sobre el nivel general de precios que se observa posteriormente y por ende sobre la inflación medida en el periodo en el que se registra el cambio. En el pasado los aumentos en los precios administrados eran menos identificables que en la actualidad, puesto que estos aumentos eran principalmente para compensar rezagos. Así, los precios administrados aportaban poca información para explicar la inflación. En la actualidad, los aumentos reales en los precios administrados son más 
identificables e independientes y por ello representan una mayor influencia sobre la inflación. En la siguiente sección se determinan las condiciones necesarias para pronosticar aumentos en precios administrados.

\section{Gráfica 4}

Funciones de impulso respuesta para 1992 a 1996

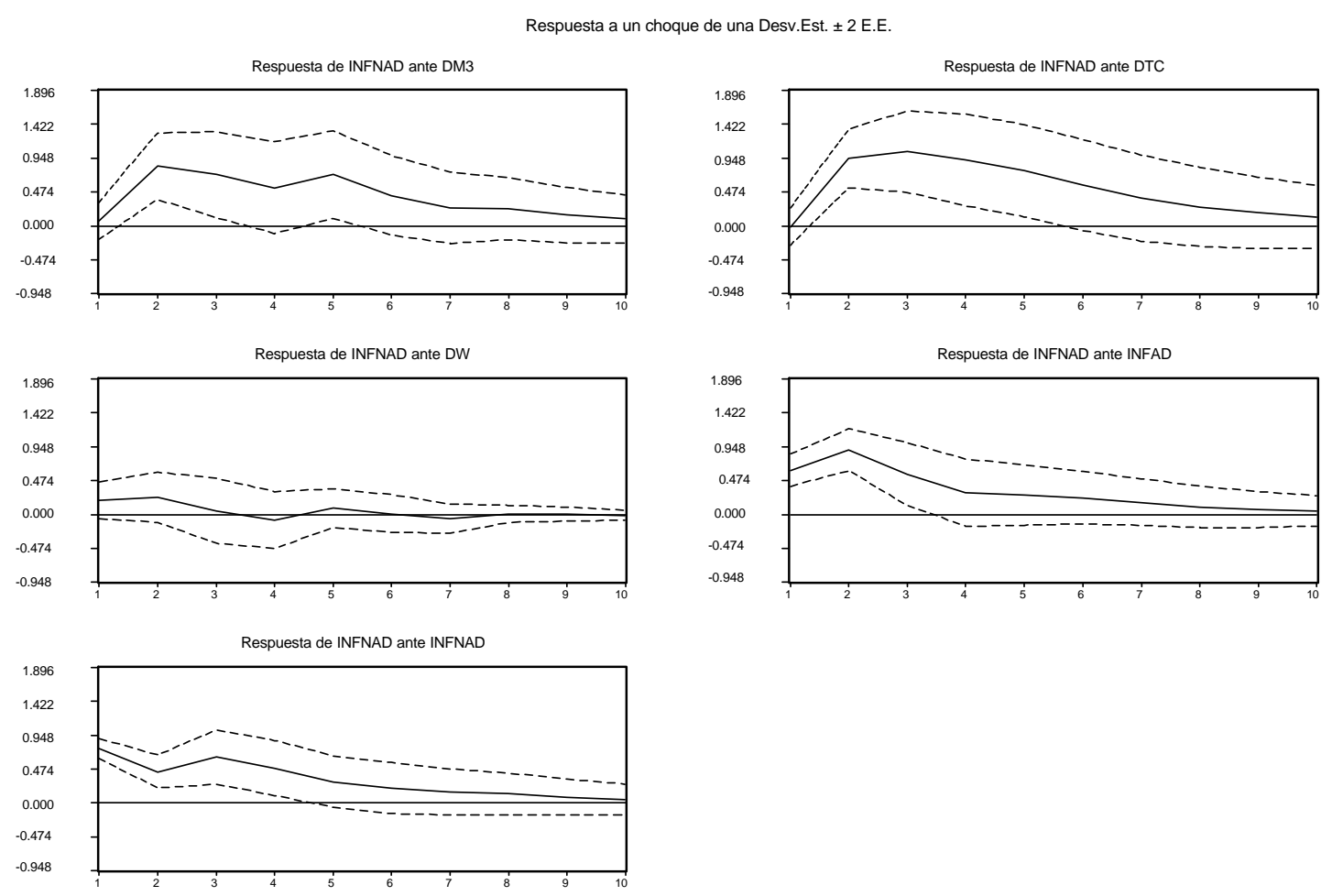

\section{AJUSTES EN PRECIOS ADMINISTRADOS}

Los agentes ajustan sus precios ante los aumentos inesperados en los precios administrados, mientras que la expectativa de inflación futura de la autoridad fiscal se determina principalmente por los ajustes mensuales. Esto se debe a que las fases durante las que se predeterminan las tasas de aumento mensual con el objetivo de mantener precios reales constantes inician con aumentos superiores a la inflación para elevar el nivel del precio real del bien y no se puede precisar con certeza cuando habrá nuevas alzas en los niveles reales. Por otra parte, los otros bienes controlados que no siguen estos ajustes mensuales también tienen aumentos imprevisibles. En la gráfica 2 se muestra que en promedio los niveles reales de los precios administrados han subido en los últimos años. A partir de 1992 disminuyó la variabilidad de estos precios reales, ya que sólo ocasionalmente tuvieron ajustes en sus niveles reales. Sin embargo, estos ajustes pueden ser de una magnitud considerable, de tal forma que aumentos del $20 \%$ en términos reales en estos bienes no son inverosímiles. En la gráfica 5 se pueden apreciar instancias en las que periodos de más de dos años con un precio real estable son seguidas de un precio real distinto en un $20 \%$ o más por un periodo similar.

\section{Gráfica 5}

Algunos Precios Administrados en Términos Reales (el Promedio es Igual a 1). 

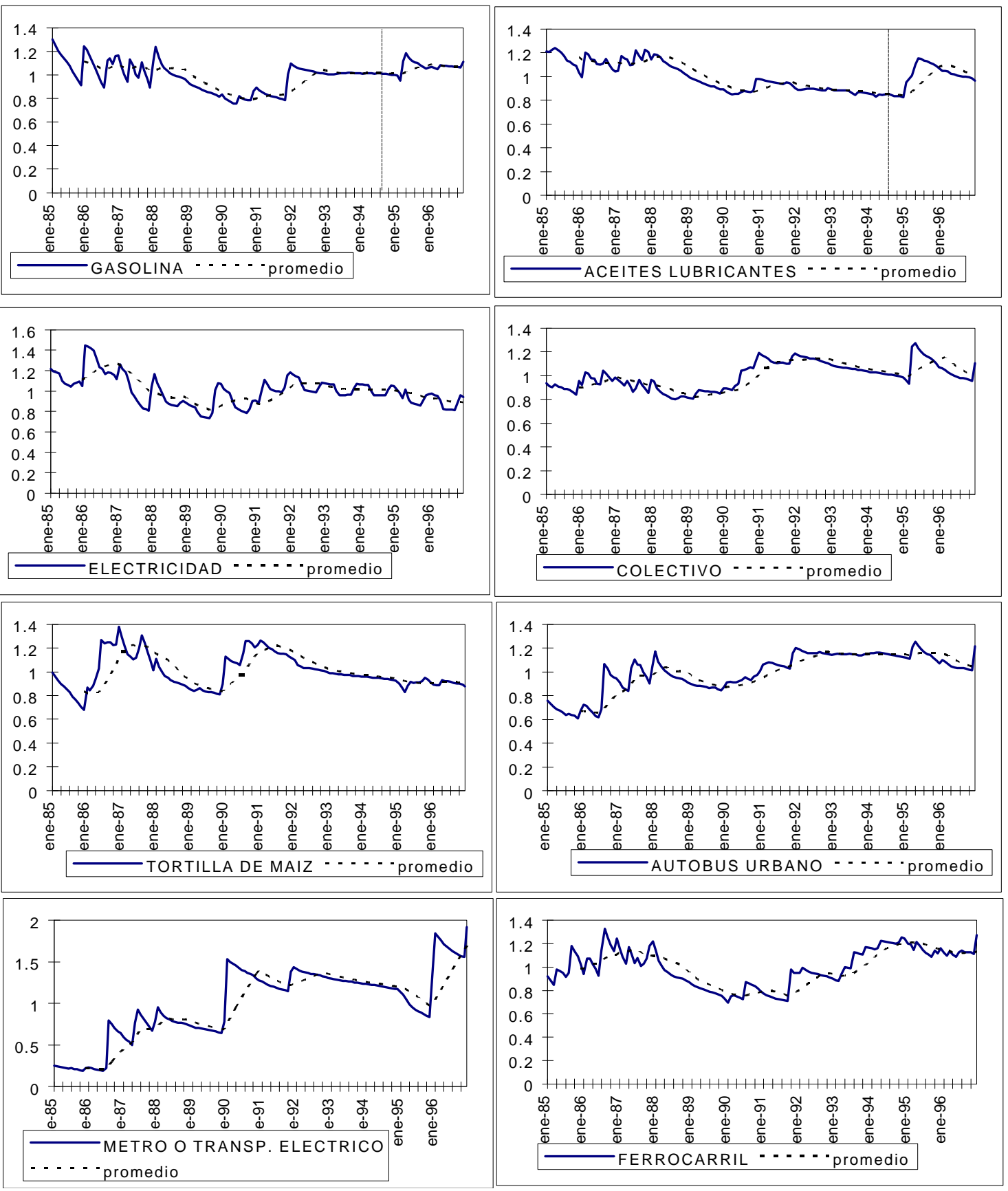

El que se mantengan niveles reales tan distintos por largos periodos se debe a los cambios en las políticas de subsidios que afectan a estos bienes. Por ejemplo, antes de diciembre de 1996, el último aumento al precio nominal de la tortilla se había registrado en 1991, ocasionando con ello una caída del $40 \%$ en su precio real. El alza de enero de 1997 del 10\% no resultó suficiente para compensar esta caída y era de esperarse un alza adicional, que resultó de poco más del $10 \%$ en septiembre de ese mismo año. Es tan probable que se presente un ajuste adicional el año que sigue, como que se liberalice, o como que no se tenga aumento sino hasta 1999. Un observador que no tenga acceso a la determinación de la política en materia de los 
subsidios a las tortillas, electricidad, gas o transporte público, tendría dificultad para pronosticar aumentos en precios administrados.

De hecho y como se muestra en la gráfica 5, la estimación del posible cambio en precios administrados por métodos estadísticos es poco confiable. Estos precios no tienden a moverse alrededor de lo que podría considerarse como un precio relativo de equilibrio y tampoco tienen un comportamiento cíclico regular que permita anticipar sus movimientos con un alto grado de confianza.

\section{CONCLUSIONES}

El sector público participa en la determinación del precio de bienes que él mismo produce y de algunos bienes con fuerte impacto en el consumo de los habitantes de menores ingresos. En la actualidad, el $16 \%$ del gasto de los consumidores se realiza en bienes que tienen precios administrados.

Los precios administrados influyen sobre la inflación, ya sea porque ocasionan fuertes variaciones en los precios relativos o porque funcionan como señal de la inflación futura. Hasta antes de 1992 los ajustes en precios administrados eran de fuerte magnitud y esporádicos, por lo que la variabilidad de precios relativos era una causa considerable de inflación en el corto plazo. Después de ese año, con la liberalización de productos que constituyen el $20 \%$ del gasto de los consumidores y la política de sostener el nivel real de los precios públicos con aumentos mensuales conforme a la inflación prevista, la variabilidad de precios disminuyó, pero al hacerse más públicos y transparentes sus incrementos, aumentó el papel de los precios públicos como señal de la inflación futura.

En épocas más recientes, los aumentos en precios públicos han registrado un mayor efecto sobre los aumentos de los precios no administrados. El efecto señal de inflación se deduce de que, en la actualidad, aumentos de $1 \%$ en los precios que estuvieron controlados durante toda la muestra ocasionan un aumento en los precios que estuvieron libres durante el mismo periodo del $0.17 \%$, mientras que este efecto era del 0.13\% durante 1985-1991. Cuando se toma en cuenta el efecto total de los aumentos en precios administrados sobre la inflación, resulta que éste es prácticamente el mismo que tenían los precios administrados cuando constituían el 36\% del gasto de los consumidores.

Los aumentos en los precios administrados son en la actualidad más independientes de los otros canales que generan aumentos en precios libres. Parte de esta independencia se debe a que se han presentado importantes aumentos en los precios relativos de algunos de estos bienes. Para evitar rezagos en los precios administrados, es conveniente que en la medida de lo posible se ajusten continuamente a sus costos marginales.

En la actualidad, los aumentos en niveles reales de los precios administrados se presentan de forma impredecible, ya que se desconoce la política de subsidios que afecta a los bienes administrados. Dado el importante efecto que los bienes administrados tienen sobre la inflación en bienes libres, por la señal que proporcionan sobre la inflación futura, es importante que sus aumentos se realicen de tal forma que sean congruentes con el pronóstico de inflación proporcionado por la autoridad. 
El efecto señal de los precios administrados muestra el poder de los anuncios de política sobre las expectativas de inflación de los agentes, lo que indica la viabilidad de utilizar una meta de inflación como ancla de precios en un esquema de objetivos de inflación. En este contexto, sería recomendable incluir a los precios administrados en la meta inflacionaria, pese a los efectos encontrados en este trabajo. Eliminar a los precios administrados del índice sobre el cual se determina la inflación objetivo mermaría la credibilidad de la autoridad en el cumplimiento de su función y no eliminaría el efecto de las alzas en precios administrados por encima del objetivo de inflación sobre el resto de los precios, debido a que los efectos de los precios administrados se extienden a otros bienes. 


\section{REFERENCIAS}

Ball, Lawrence y Gregory Mankiw (1995). "Relative-Price Changes as Aggregate Supply Shocks". Quarterly Journal of Economics.

Bruno, Michael. "High Inflation and the Nominal Anchors of an Open Economy". NBER Working Paper \#3518. November 1990.

Coorey, Sharmini, Mauro Mecagni y Erik Offerdal (1997). "Designing Disinflation Programs in Transition Economies: The Implications of Relative Price Adjustment”. IMF Paper on Policy Analysis and Assesment, February 1997.

Cukierman, Alex (1988). "The End of the High Israeli Inflation: An Experiment in Heterodox Stabilization". En Bruno, Di Tella, Dornbusch y Fischer eds., Inflation Stabilization: Argentina, Israel, Brazil, Bolivia and Mexico, MIT Press, 1988, pp. 48-93.

Cukierman, Alex y Leonardo Leiderman (1984). "Price Controls and the Variability of Relative Prices”. Journal of Money, Credit and Banking, August 1984, pp. 271-284.

Dávila, Claudia (1991). Control y Administración de Precios durante el Programa de Estabilización (PSE y PECE). Estimación de Rezagos en Precios de Productos Alimenticios, 1991. Tesis de Licenciatura. ITAM.

Fischer, Stanley (1981). "Relative Shocks, Relative Price Variability, and Inflation". Brookings Papers on Economic Activity, 2:1981. pp. 381-441.

Gil Díaz, Francisco (1983) “Mexico’s Pata from Stability to Inflation”. Trabajo presentado en la conferencia World Economic Growth auspiciada por el Institute for Contemporary Studies.

Hamilton, James D. (1994). Time Series Analysis. Princeton University Press.

Taylor, John (1983). "Union wage settlements during a disinflation" American Economic Review. 73. December, 1983. pp. 981-993.

Veruete, Leticia y Jaime Villaseñor (1988). Variabilidad de Precios Relativos, Inflación y Control de Precios: Un Caso para México; Enero de 1980 a Junio de 1987. Tesis de Licenciatura. ITAM.

Vining, Daniel Jr. y Thomas Elwertowski (1976). “The Relationship between Relative Prices and the General Price Level”. American Economic Review. September, 1976. pp. 699-708. 


\section{Anexo 1}

PRODUCTOS BAJO CONTROL DE PRECIOS

Diario Oficial de la Federación (30 de Diciembre de 1982)

\begin{tabular}{|c|c|c|c|}
\hline & SECOFI & SHCP & LIBERADO \\
\hline Aceites y grasas de origen vegetal & $\mathrm{X}$ & & 21-may-93 \\
\hline Agua purificada & $\mathrm{X}$ & & $16-a b r-93$ \\
\hline Alimentos preparados para niños & $\mathrm{X}$ & & 21-may-93 \\
\hline Arroz & $\mathrm{X}$ & & 19-nov-93 \\
\hline Atún enlatado & $\mathrm{X}$ & & 16-abr-93 \\
\hline Avena & $\mathrm{X}$ & & $16-a b r-93$ \\
\hline Azúcar & $\mathrm{X}$ & & 25-ago-95 \\
\hline Café & $\mathrm{X}$ & & 19-nov-93 \\
\hline Carne de ganado vacuno & $\mathrm{X}$ & & 26-nov-93 \\
\hline Jamón & $\mathrm{X}$ & & 21-may-93 \\
\hline Chocolate en polvo & $\mathrm{X}$ & & 16 -abr-93 \\
\hline Frijol & $\mathrm{X}$ & & 30-mar-94 \\
\hline Frutas y legumbres envasadas & $\mathrm{X}$ & & 21-may-93 \\
\hline Galletas & $\mathrm{X}$ & & 16 -abr-93 \\
\hline Harina de Maíz & $\mathrm{X}$ & & \\
\hline Harina de Trigo & $\mathrm{X}$ & & 30-mar-94 \\
\hline Huevo & $\mathrm{X}$ & & 19-nov-93 \\
\hline $\begin{array}{l}\text { Leche pasteurizada en polvo, } \\
\text { condensada, evaporada y pasteurizada }\end{array}$ & $\mathrm{X}$ & & 27-dic-96 \\
\hline Maíz & $\mathrm{X}$ & & 30-mar-94 \\
\hline Masa de Maíz & $X$ & & 21-may-93 \\
\hline Pan: bolillo y telera & $\mathrm{X}$ & & 30-mar-94 \\
\hline Pan de caja & $\mathrm{X}$ & & 19-nov-93 \\
\hline Pastas alimentación para sopa & $\mathrm{X}$ & & 21-may-93 \\
\hline Pescado & $\mathrm{X}$ & & 21-may-93 \\
\hline Refresco en envase de cualquier naturaleza & $\mathrm{X}$ & & 26-nov-93 \\
\hline Sal & $\mathrm{X}$ & & 16-abr-93 \\
\hline Sardina conservada en envase de cualquier naturaleza & $\mathrm{X}$ & & 21-may-93 \\
\hline Tortilla de maíz & $\mathrm{X}$ & & \\
\hline Trigo & $\mathrm{X}$ & & 26-nov-93 \\
\hline Productos petroquímicos primarios & & $\mathrm{X}$ & 30-mar-94 \\
\hline Alimentos balanceados & $\mathrm{X}$ & & $16-a b r-93$ \\
\hline Harina de Pescado & $\mathrm{X}$ & & $16-a b r-93$ \\
\hline Gas licuado & & $\mathrm{X}$ & 30-mar-94 \\
\hline Gas natural & & $\mathrm{X}$ & 30-mar-94 \\
\hline Diesel & & $\mathrm{X}$ & 30-mar-94 \\
\hline Gasolinas varias & & $\mathrm{X}$ & 30-mar-94 \\
\hline Calentadores de agua para el hogar & $\mathrm{X}$ & & $16-a b r-93$ \\
\hline Estufas de gas & $\mathrm{X}$ & & $16-a b r-93$ \\
\hline Estufas de petróleo & $\mathrm{X}$ & & $16-a b r-93$ \\
\hline Lavadoras de ropa & $\mathrm{X}$ & & 21-may-93 \\
\hline Licuadoras & $\mathrm{X}$ & & 21-may-93 \\
\hline Máquinas de coser & $\mathrm{X}$ & & 21-may-93 \\
\hline Parrillas eléctricas & $\mathrm{X}$ & & $16-a b r-93$ \\
\hline Planchas & $\mathrm{X}$ & & 16 -abr-93 \\
\hline Radios & $\mathrm{X}$ & & 21-may-93 \\
\hline
\end{tabular}




\section{Anexo 1}

PRODUCTOS BAJO CONTROL DE PRECIOS

Diario Oficial de la Federación (30 de Diciembre de 1982)

\begin{tabular}{|c|c|c|c|}
\hline & SECOFI & SHCP & LIBERADO \\
\hline Bolígrafos & $\mathrm{X}$ & & 19-nov-93 \\
\hline Botellas y frascos & $\mathrm{X}$ & & 21-may-93 \\
\hline Cuadernos & $\mathrm{X}$ & & 21-may-93 \\
\hline Servilletas & $\mathrm{X}$ & & 19-nov-93 \\
\hline Detergentes & $\mathrm{X}$ & & 19-nov-93 \\
\hline Focos & $\mathrm{X}$ & & 19-nov-93 \\
\hline Jabón de lavandería & $\mathrm{X}$ & & 26-nov-93 \\
\hline Jabones de tocador & $\mathrm{X}$ & & 26-nov-93 \\
\hline Lápices & $\mathrm{X}$ & & 26-nov-93 \\
\hline Medicinas de todas clases & $\mathrm{X}$ & & \\
\hline Papel de todas clases para todos los usos & $\mathrm{X}$ & & 26-nov-93 \\
\hline Pastas dentífricas & $\mathrm{X}$ & & 26-nov-93 \\
\hline Pilas y baterías & $\mathrm{X}$ & & 26-nov-93 \\
\hline Autobuses & $\mathrm{X}$ & & 26-nov-93 \\
\hline Automóviles & $\mathrm{X}$ & & 26-nov-93 \\
\hline Camiones & $\mathrm{X}$ & & 26-nov-93 \\
\hline Tractores agrícolas & $\mathrm{X}$ & & 26-nov-93 \\
\hline Cereales preparados derivados de maíz, arroz y trigo & $\mathrm{X}$ & & 21-may-93 \\
\hline Crema de leche & $\mathrm{X}$ & & 21-may-93 \\
\hline Frijol en polvo preparado & $\mathrm{X}$ & & $16-a b r-93$ \\
\hline Gelatina en polvo y granulado & $\mathrm{X}$ & & 16-abr-93 \\
\hline Jugos y néctares & $\mathrm{X}$ & & 16-abr-93 \\
\hline Mantequilla & $\mathrm{X}$ & & 16-abr-93 \\
\hline Margarina & $\mathrm{X}$ & & 21-may-93 \\
\hline Blusas & $\mathrm{X}$ & & 21-may-93 \\
\hline Brasieres & $\mathrm{X}$ & & 21-may-93 \\
\hline Calcetines y tobilleras & $\mathrm{X}$ & & 21-may-93 \\
\hline Calzado & $\mathrm{X}$ & & 21-may-93 \\
\hline Calzoncillos & $\mathrm{X}$ & & 21-may-93 \\
\hline Camisas & $\mathrm{X}$ & & 19-nov-93 \\
\hline Chamarras & $\mathrm{X}$ & & 19-nov-93 \\
\hline Faldas & $\mathrm{X}$ & & 19-nov-93 \\
\hline Pantaletas & $\mathrm{X}$ & & 19-nov-93 \\
\hline Pantalones & $\mathrm{X}$ & & 19-nov-93 \\
\hline Playeras de algodón & $\mathrm{X}$ & & 19-nov-93 \\
\hline Cepillos para la higiene dental & $\mathrm{X}$ & & 26-nov-93 \\
\hline Colchones & $\mathrm{X}$ & & 26-nov-93 \\
\hline Llantas y cámaras para todos los usos & $\mathrm{X}$ & & 26-nov-93 \\
\hline Máquinas, rastrillos y hojas para rasuradora & $\mathrm{X}$ & & 26-nov-93 \\
\hline Vidrio plano & $\mathrm{X}$ & & 26-nov-93 \\
\hline
\end{tabular}

Fuente: SECOFI 